\title{
Novel Switching Table for Direct Torque Controlled Permanent Magnet Synchronous Motors to Reduce Torque Ripple
}

\author{
Sivaprakasam Arumugam ${ }^{\dagger}$ and Manigandan Thathan ${ }^{*}$ \\ ${ }^{\dagger}$ Department of Electrical and Electronics Engineering, Kongu Engineering College, Erode, India \\ *P. A. College of Engineering and Technology, Pollachi, India
}

\begin{abstract}
The Direct Torque Control (DTC) technique for Permanent Magnet Synchronous Motors (PMSM) is receiving increased attention due to its simplicity and robust dynamic response when compared with other control techniques. The classical switching table based DTC results in large flux and torque ripples in the motors. Several studies have been reported in the literature on classical DTC. However, there are only limited studies that actually discuss or evaluate the classical DTC. This paper proposes, novel switching table / DTC methods for PMSMs to reduce torque ripples. In this paper, two DTC schemes are proposed. The six sector and twelve sector methodology is considered in DTC scheme I and DTC scheme II, respectively. In both DTC schemes a simple modification is made to the classical DTC structure. The two level inverter available in the classical DTC is eliminated by replacing it with a three level Neutral Point Clamped (NPC) inverter. To further improve the performance of the proposed DTC scheme I, the available 27 voltage vectors are allowed to form different groups of voltage vectors such as Large - Zero (LZ), Medium - Zero (MZ) and Small - Zero (SZ), where as in DTC scheme II, all of the voltage vectors are considered to form a switching table. Based on these groups, a novel switching table is proposed. The proposed DTC schemes are comparatively investigated with the classical DTC and existing literatures through theory analysis and computer simulations. The superiority of the proposed DTC method is also confirmed by experimental results. It can be observed that the proposed techniques can significantly reduces the torque ripples and improves the quality of current waveform when compared with traditional and existing methods.
\end{abstract}

Key words: AC motor drives, Direct torque control, Synchronous motor drives, Total Harmonic Distortion

\section{INTRODUCTION}

In 1971 F. Blaschke proposed the concept of Field Oriented Control (FOC) for Induction Motors [1]. Since, that time, the FOC has dominated in the advanced AC drive market, even though it has complicated structure. Thirteen years later, a new control technique for the Torque Control of Induction Motors was proposed by I. Takahashi and T. Noguchi in the form of Direct Torque Control (DTC) [2]. Two years later M. Depenbrock presented another control technique referred to as Direct Self Control (DSC) [3]. The first follows a Circular Trajectory and later follows a

Manuscript received Mar. 16, 2103; revised Jul. 24, 2013

Recommended for publication by Associate Editor Dong-Hee Lee.

${ }^{\dagger}$ Corresponding Author: sivaa_prakasam@yahoo.com

Tel: +91-98655-21041, Kongu Engineering College

*P.A. College of Engineering and Technology, India
Hexagon Trajectory. Both of them proved that it is possible to obtain a good dynamic control of torque without sensors on the mechanical shaft. Thus DTC and DSC can be considered as sensorless type control techniques.

The DTC scheme is normally preferred for low and medium power applications, where as DSC scheme is preferred for high power applications. In this paper, attention is focused on the DTC, which is best suited for low and medium power applications. The DTC overcomes the drawbacks of FOC such as the requirements of current regulators, co-ordinate transformations and PWM signal generators. DTC also provides high efficiency, high power / torque density and high reliability [4]-[7]. Due to its simplicity, DTC allows a good torque control in both the steady state and the dynamic state.

On the other hand, the classical DTC, has some disadvantages such as: 
1) difficulty controlling the torque at very low speed

2) high current and torque ripples

Most of the surveyed studies [8]-[17] have analyzed classical DTC using a two level inverter and all of them have presented a high degree of torque ripple under dynamic conditions and this is reflected in the speed and current too. In this paper, the possibilities for the minimization of torque ripple in DTC is the focus. The minimization of torque ripple is achieved by improvements in the following areas, the inverter, number of sectors and switching table.

In this paper, the conventional two level inverter is replaced by a three level Neutral Point Diode Clamped (NPC) inverter which has 27 voltage vectors, where as only 8 voltage vectors were available with the classical DTC. In the 27 voltage vectors, there are six large and six medium voltage vectors, twelve small voltage vectors and three zero voltage vectors.

Some studies [18]-[24] presented three level inverters with classical DTC, but they utilized all 27 voltage vectors to construct the switching table. The authors of [29] used a Fuzzy Logic Controller to reduce torque ripple by adjusting the bandwidth of the hysteresis torque controller. In order to maintain a constant switching frequency the width of the hysteresis band was analytically calculated and optimized by the authors of [30]. The width of the hysteresis band was set to zero in most of the studies to reduce the torque ripple. In this paper the hysteresis bandwidth is set to zero. This paper also proposes four kind of DTC methods to reduce torque ripple. In DTC method 1, only the large and zero voltage vectors are used to construct a switching table, where as in DTC method 2, the medium and zero voltage vectors alone are utilized to construct a switching table. The small and zero voltage vectors are considered to form a switching table for DTC method 3. In DTC method 4 all the voltage vectors are considered for a switching table.

Thus based on the experience of the authors, a fair comparison between all the methods is presented in both steady state and external load disturbance / dynamic conditions. This comparison is useful to indicate to users which of the methods can be effectively utilized for various applications that require torque control.

\section{VOLTAGE Vector IMPACT ON TORQUE}

An understanding of the effect of the voltage vector on the torque is mandatory for torque control. According to the principle of DTC, the electrical angle between the stator and rotor flux vectors, $\delta$ can control the torque developed by the PMSM. In the background this can be achieved by controlling the voltage vector. Hence, the voltage vector is the prime controllable input variable in DTC. However, it is mandatory to develop a relation between the torque developed by the PMSM and the voltage vector.
The voltage and stator flux equations in the stationary frame are expressed as:

$$
\begin{gathered}
U_{s}=\frac{d \varphi_{s}}{d t}+R_{s} i_{s} . \\
\varphi_{s}=L_{s} i_{s}+\varphi_{r}
\end{gathered}
$$

From (1) and (2), the following are obtained:

$$
\begin{gathered}
L_{s} \frac{d i_{s}}{d t}=U_{s}-R_{s} i_{s}-\frac{d \varphi_{r}}{d t} \\
L_{s} \frac{d i_{s}}{d t}=U_{s}-R_{s} i_{s}-j \omega \varphi_{r}
\end{gathered}
$$

In the DTC of PMSMs, it is necessary to develop the relationship between the input voltage and the developed torque. The torque developed by the PMSM in the stationary frame is expressed as:

$$
T_{e}=\frac{3}{2} p \varphi_{s} \times i_{s}
$$

Differentiating (5) with respect to time $t$ results in:

$$
\frac{d T_{e}}{d t}=\frac{3}{2} p\left\{\left(\frac{d \varphi_{s}}{d t} \times i_{s}\right)+\left(\frac{d i_{s}}{d t} \times \varphi_{s}\right)\right\}
$$

Substituting (1), (2) and (4) into (6), yields:

$$
\begin{gathered}
L_{s} \frac{d T_{e}}{d t}=\frac{3}{2} p \varphi_{r} \times U_{s}-\frac{3}{2} p \omega \varphi_{r} \bullet \varphi_{s}-R_{s} T_{e} \\
L_{s} \frac{d T_{e}}{d t}=T_{e I}+T_{e I I}+T_{e I I I}
\end{gathered}
$$

Where:

$\begin{array}{ll}\varphi_{s}, \varphi_{r} & \text { Stator and Rotor flux vectors } \\ U_{s}, i_{s} & \text { Stator voltage and Current vector } \\ R_{s}, L_{s} & \text { Stator resistance and Synchronous inductance } \\ p & \text { Number of pole pairs } \\ T_{e} & \text { Electromagnetic torque } \\ \omega & \text { Electrical rotor speed }\end{array}$

It can be seen from (7), that the equation contains three components [25] - [27]. The second component is negative and is a function of speed. The third component is also negative and depends on the stator resistance. The first component is always positive and depends on the voltage vector. From this, it is concluded that the non-zero vectors always increases the developed torque and the zero vectors always decreases the developed torque.

\section{Classical DTC}

Based on the errors between the reference and actual values of the torque and flux, it is possible to directly control the inverter switching states in order to reduce the torque and flux errors within prefixed band limits. That is why this technique is called Direct Torque Control. A block diagram of the classical DTC for PMSMs is shown in Fig. 1.

The basic principle of DTC is to select stator voltage 


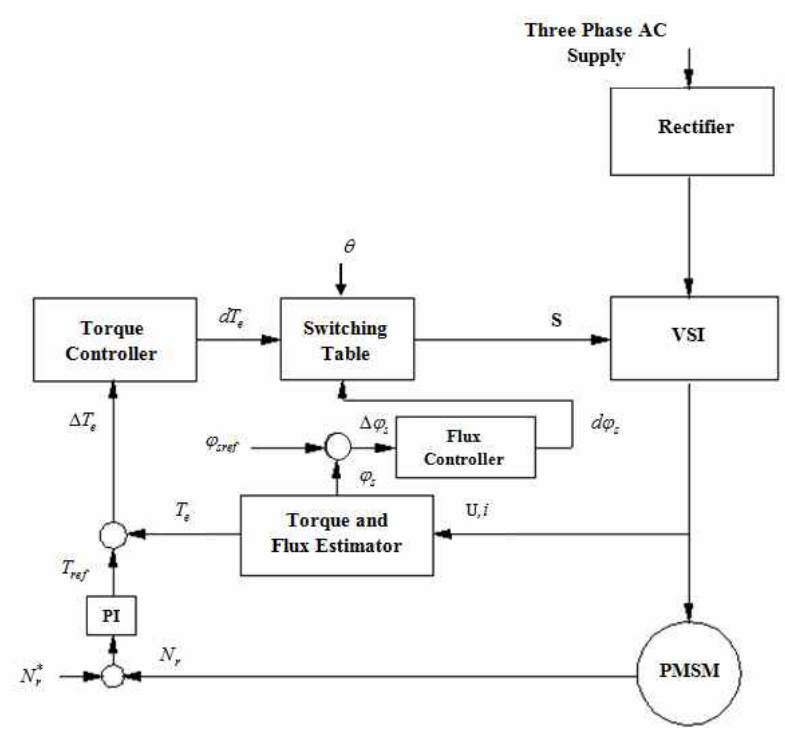

Fig. 1. Block diagram of the classical DTC.

vectors according to the differences between the reference and actual torques. The reference and actual values of the stator flux are processed through a two level hysteresis comparator. If the error is positive, the magnitude of the flux has to be increased and is denoted as $d \varphi_{s}=1$. If the error is negative, the magnitude of the flux has to be decreased and is denoted as $d \varphi_{s}=0$. The flux comparator conditions are given as:

$$
\begin{array}{ll}
d \varphi_{s}=1 \text { for } & \left|\varphi_{s}\right| \leq\left|\varphi_{\text {sref }}\right|-\left|\Delta \varphi_{S}\right| \\
d \varphi_{s}=0 \text { for } & \left|\varphi_{s}\right| \geq\left|\varphi_{\text {sref }}\right|+\left|\Delta \varphi_{s}\right|
\end{array}
$$

The rotor reference speed is compared with the actual rotor speed and the error obtained is converted into reference torque by using a suitable PI regulator.

The reference and actual torques are processed through a three level hysteresis comparator. If the error is positive, the magnitude of the torque has to be increased and is denoted as $\mathrm{dT}_{\mathrm{e}}=1$. If the error is negative, the magnitude of the torque has to be decreased and is denoted as $\mathrm{dT}_{\mathrm{e}}=-1$. If the error is zero, the magnitude of the torque has to be kept constant and is denoted as $\mathrm{dT}_{\mathrm{e}}=0$. The torque comparator conditions are given as:

$$
\begin{array}{ll}
d T_{e}=1 \text { for } & \left|T_{e}\right| \leq\left|T_{\text {ref }}\right|-\left|\Delta T_{e}\right| \\
d T_{e}=-1 \text { for } & \left|T_{e}\right| \geq\left|T_{r e f}\right|+\left|\Delta T_{e}\right| \\
d T_{e}=0 \text { for } & \left|T_{r e f}\right|-\left|\Delta T_{e}\right| \leq\left|T_{e}\right| \leq\left|T_{r e f}\right|+\left|\Delta T_{e}\right|
\end{array}
$$

Finally, the most suitable voltage vectors are selected form the switching table based on the flux and torque errors for all of the sectors.
TABLE I

TeChnical Difference among the Classical and Proposed DTC SCHEMES

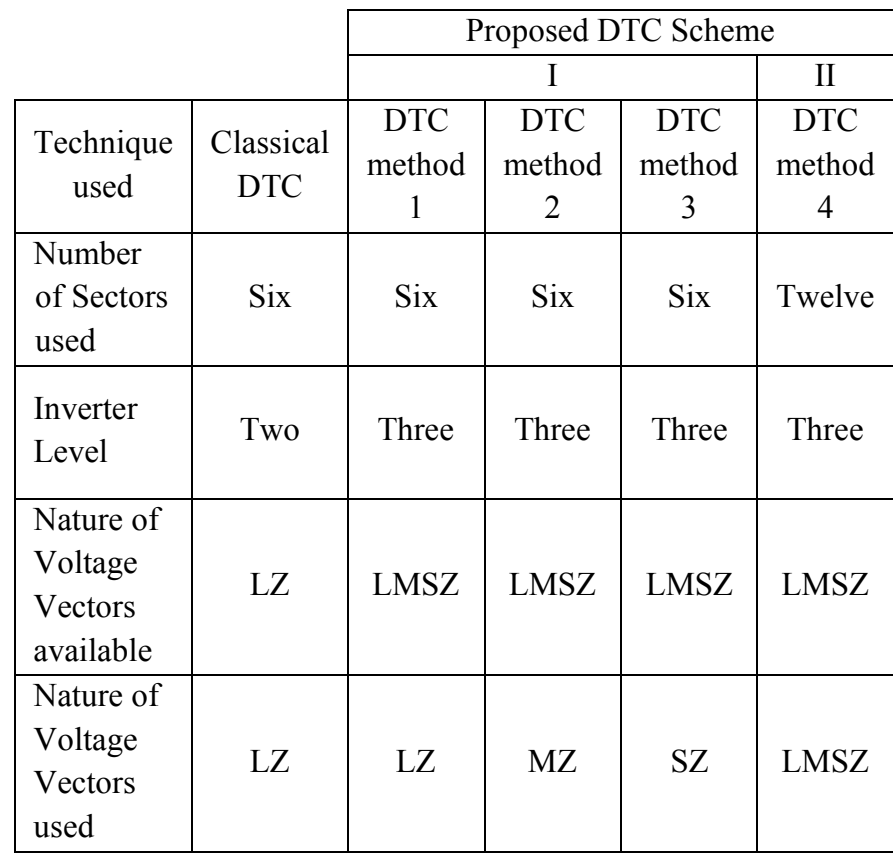

\section{PROPOSED DTC METHOD}

The classical DTC uses a two level inverter and produces only eight voltage vectors which includes six non-zero vectors and two zero vectors. This does not allow for a smooth variation in the flux and torque. This could be one of the main reason for large flux and torque ripples.

In this proposed DTC method, the two level inverter is replaced by a NPC three level inverter. Due to the increment in the level of the inverter, there are 27 voltage vectors available to construct the switching table. Among these there are six large vectors (V1, V3, V5, V7, V9, V11), six medium vectors (V2, V4, V6, V8, V10, V12), three vectors (V0, V25, V26) and twelve small vectors. The inference from section 3 is that the switching table plays an important role in the DTC technique. For a proper switching table the best result can be obtained. The structure of the proposed DTC schemes is shown in Fig. 2. The proposed DTC methods provides satisfactory results when compared to classical DTC. Table I shows the technical data for the proposed DTC schemes.

In the proposed DTC schemes, the stator flux reference is calculated from the torque reference based on the Maximum Torque per Ampere (MTPA) principle to increase the efficiency of the system [7]. In the conventional method, the stator flux reference is calculated offline by using the machine parameters. In this paper, the stator flux reference is calculated in the online mode by substituting the instantaneous value of the torque reference in equation (14). 
TABLE II

SWitching TABLe For Proposed DTC Method 1

\begin{tabular}{|c|c|c|c|c|c|c|c|}
\hline$d \varphi_{s}$ & $d T_{e}$ & $\theta(1)$ & $\theta(2)$ & $\theta(3)$ & $\theta(4)$ & $\theta(5)$ & $\theta(6)$ \\
\hline \multirow{2}{*}{1} & 1 & V3 & V5 & V7 & V9 & V11 & V1 \\
\cline { 2 - 8 } & 0 & V0 & V26 & V0 & V26 & V0 & V26 \\
\cline { 2 - 8 } & -1 & V11 & V1 & V3 & V5 & V7 & V9 \\
\hline \multirow{2}{*}{0} & 1 & V5 & V7 & V9 & V11 & V1 & V3 \\
\cline { 2 - 8 } & 0 & $\mathrm{~V} 0$ & $\mathrm{~V} 26$ & V0 & V26 & V0 & V26 \\
\cline { 2 - 8 } & -1 & $\mathrm{~V} 9$ & $\mathrm{~V} 11$ & $\mathrm{~V} 1$ & $\mathrm{~V} 3$ & $\mathrm{~V} 5$ & $\mathrm{~V} 7$ \\
\hline
\end{tabular}

TABLE III

Switching TABLE for Proposed DTC Method 2

\begin{tabular}{|c|c|c|c|c|c|c|c|}
\hline$d \varphi_{s}$ & $d T_{e}$ & $\theta(1)$ & $\theta(2)$ & $\theta(3)$ & $\theta(4)$ & $\theta(5)$ & $\theta(6)$ \\
\hline \multirow{2}{*}{1} & 1 & $\mathrm{~V} 4$ & $\mathrm{~V} 6$ & $\mathrm{~V} 8$ & $\mathrm{~V} 10$ & $\mathrm{~V} 12$ & $\mathrm{~V} 2$ \\
\cline { 2 - 8 } & 0 & $\mathrm{~V} 0$ & $\mathrm{~V} 26$ & $\mathrm{~V} 0$ & $\mathrm{~V} 26$ & $\mathrm{~V} 0$ & $\mathrm{~V} 26$ \\
\cline { 2 - 8 } & -1 & $\mathrm{~V} 12$ & $\mathrm{~V} 2$ & $\mathrm{~V} 4$ & $\mathrm{~V} 6$ & $\mathrm{~V} 8$ & $\mathrm{~V} 10$ \\
\hline \multirow{2}{*}{0} & 1 & $\mathrm{~V} 6$ & $\mathrm{~V} 8$ & $\mathrm{~V} 10$ & $\mathrm{~V} 12$ & $\mathrm{~V} 2$ & $\mathrm{~V} 4$ \\
\cline { 2 - 8 } & 0 & $\mathrm{~V} 0$ & $\mathrm{~V} 26$ & $\mathrm{~V} 0$ & $\mathrm{~V} 26$ & $\mathrm{~V} 0$ & $\mathrm{~V} 26$ \\
\cline { 2 - 8 } & -1 & $\mathrm{~V} 10$ & $\mathrm{~V} 12$ & $\mathrm{~V} 2$ & $\mathrm{~V} 4$ & $\mathrm{~V} 6$ & $\mathrm{~V} 8$ \\
\hline
\end{tabular}

$$
\left|\varphi_{\text {sref }}\right|=\sqrt{\varphi_{f}^{2}+\left(\frac{L_{q} T_{r e f}}{\frac{3}{2} p \varphi_{f}}\right)}
$$

\section{A. DTC Method 1}

The proposed DTC scheme I includes DTC method 1, DTC method 2 and DTC method 3. In addition, the six sector methodology is considered in this scheme. The proposed DTC method 1 utilizes large and zero voltage vectors. In this method 9 voltage vectors are used where 6 of them are large voltage vectors and 3 of them are zero voltage vectors. This method is almost an imitation of the classical DTC, because in both cases only large and zero voltage vectors used. The switching table is constructed using these 9 voltage vectors. The switching table developed in this method is similar to the classical DTC switching table. The drawback of the classical DTC is repeated in this method, due to the non-availability of intermediate voltage vectors. The switching table of the proposed DTC method 1 is shown in Table II.

\section{B. DTC Method 2}

In the proposed DTC method 2, medium and zero voltage vectors are used to construct the switching table. In this method, there are 6 medium voltage vectors and 3 zero voltage vectors. In DTC method 1, large and zero voltage vectors are used, which means the switching is between large voltage vectors and zero voltage vectors. This will produce

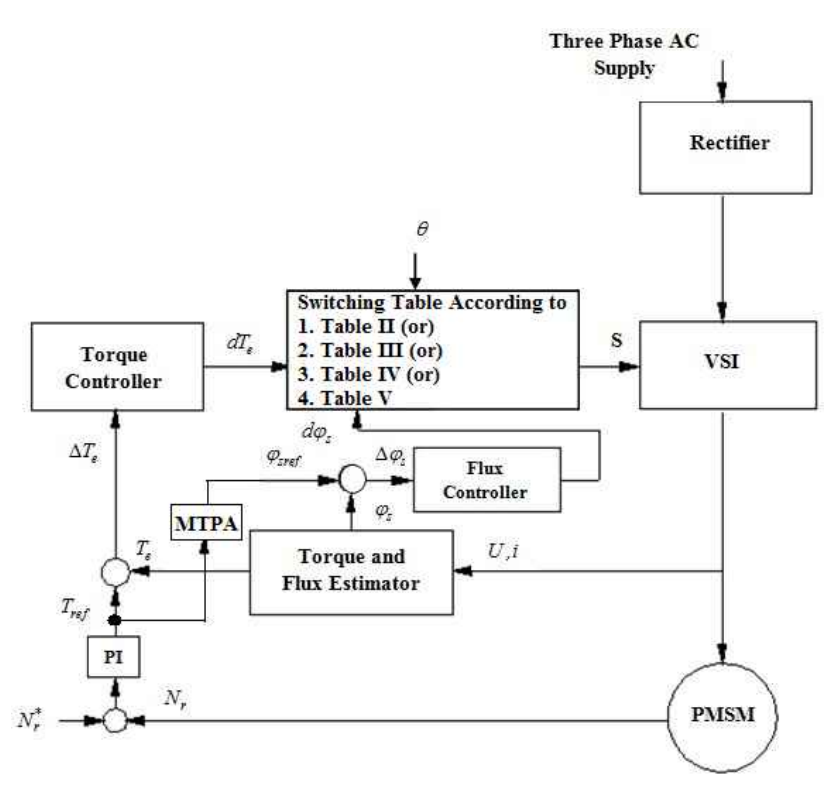

Fig. 2. Block diagram of the classical DTC.

large ripples in the flux and torque. However, in DTC method 2 , medium and zero voltage vectors are used, so the ripples in the flux and torque are considerably reduced when compared to DTC method 1. This can be observed from Fig. 8 - Fig. 12.

\section{DTC Method 3}

DTC method 2 produces slightly less torque ripple when compared to the classical DTC method and DTC method 1. This is because no large voltage vectors used in this method. From the experience of the previous methods, it can be seen that the switching of vector plays an important role in the flux and torque ripple reduction. The switching from zero voltage to large / medium voltage increases the ripples in the flux and torque, as well as the harmonic content and stress across the switching devices.

To overcome these problems, an appropriate switching table is constructed using only small and zero voltage vectors. Equation (7) tells us that the large voltage vectors contributing to torque in the same direction will lead to large errors in the actual torque. This is true for small voltage vectors as well. However, lesser torque ripples can be expected by combining small and zero voltage vectors. There are 12 small voltage vectors and 3 zero voltage vectors available in this method. The small voltage vectors exist in redundant pairs i.e. six positive small vector and six negative small vector. As a result, the switching table is formed either by using positive small vectors or negative small vectors in order to balance the neutral point potential. The small voltage vectors are selected to meet the demand of the flux and torque, as well as to reduce the flux, torque ripples and mechanical vibrations. This ensures the safe operation of the entire system. 
TABLE IV

SWitChing TABLE FOR Proposed DTC METHOD 3

\begin{tabular}{|c|c|c|c|c|c|c|c|}
\hline$d \varphi_{s}$ & $d T_{e}$ & $\theta(1)$ & $\theta(2)$ & $\theta(3)$ & $\theta(4)$ & $\theta(5)$ & $\theta(6)$ \\
\hline \multirow{3}{*}{1} & 1 & $\mathrm{~V} 15$ & $\mathrm{~V} 17$ & $\mathrm{~V} 19$ & $\mathrm{~V} 21$ & $\mathrm{~V} 23$ & $\mathrm{~V} 13$ \\
\cline { 2 - 8 } & 0 & $\mathrm{~V} 0$ & $\mathrm{~V} 26$ & $\mathrm{~V} 0$ & $\mathrm{~V} 26$ & $\mathrm{~V} 0$ & $\mathrm{~V} 26$ \\
\cline { 2 - 8 } & -1 & $\mathrm{~V} 23$ & $\mathrm{~V} 13$ & $\mathrm{~V} 15$ & $\mathrm{~V} 17$ & $\mathrm{~V} 19$ & $\mathrm{~V} 21$ \\
\hline \multirow{3}{*}{0} & 1 & $\mathrm{~V} 17$ & $\mathrm{~V} 19$ & $\mathrm{~V} 21$ & $\mathrm{~V} 23$ & $\mathrm{~V} 13$ & $\mathrm{~V} 15$ \\
\cline { 2 - 8 } & 0 & $\mathrm{~V} 0$ & $\mathrm{~V} 26$ & $\mathrm{~V} 0$ & $\mathrm{~V} 26$ & $\mathrm{~V} 0$ & $\mathrm{~V} 26$ \\
\cline { 2 - 8 } & -1 & $\mathrm{~V} 21$ & $\mathrm{~V} 23$ & $\mathrm{~V} 17$ & $\mathrm{~V} 19$ & $\mathrm{~V} 21$ & $\mathrm{~V} 23$ \\
\hline
\end{tabular}

TABLE V

Switching Table For Proposed DTC Method 4

\begin{tabular}{|c|c|c|c|c|c|c|c|}
\hline$d \varphi_{s}$ & $d T_{e}$ & $\theta(1)$ & $\theta(2)$ & $\theta(3)$ & $\theta(4)$ & $\theta(5)$ & $\theta(6)$ \\
\hline \multirow{2}{*}{1} & 1 & $\mathrm{~V} 3$ & $\mathrm{~V} 16$ & $\mathrm{~V} 5$ & $\mathrm{~V} 18$ & $\mathrm{~V} 7$ & $\mathrm{~V} 20$ \\
\cline { 2 - 8 } & 0 & $\mathrm{~V} 0$ & $\mathrm{~V} 26$ & $\mathrm{~V} 0$ & $\mathrm{~V} 26$ & $\mathrm{~V} 0$ & $\mathrm{~V} 26$ \\
\cline { 2 - 8 } & -1 & $\mathrm{~V} 12$ & $\mathrm{~V} 24$ & $\mathrm{~V} 2$ & $\mathrm{~V} 14$ & $\mathrm{~V} 4$ & $\mathrm{~V} 16$ \\
\hline \multirow{2}{*}{0} & 1 & $\mathrm{~V} 5$ & $\mathrm{~V} 18$ & $\mathrm{~V} 7$ & $\mathrm{~V} 20$ & $\mathrm{~V} 9$ & $\mathrm{~V} 22$ \\
\cline { 2 - 8 } & 0 & $\mathrm{~V} 26$ & $\mathrm{~V} 0$ & $\mathrm{~V} 26$ & $\mathrm{~V} 0$ & $\mathrm{~V} 26$ & $\mathrm{~V} 0$ \\
\cline { 2 - 8 } & -1 & $\mathrm{~V} 10$ & $\mathrm{~V} 22$ & $\mathrm{~V} 12$ & $\mathrm{~V} 24$ & $\mathrm{~V} 2$ & $\mathrm{~V} 14$ \\
\hline
\end{tabular}

\begin{tabular}{|c|c|c|c|c|c|c|c|}
\hline$d \varphi_{s}$ & $d T_{e}$ & $\theta(7)$ & $\theta(8)$ & $\theta(9)$ & $\theta(10)$ & $\theta(11)$ & $\theta(12)$ \\
\hline \multirow{2}{*}{1} & 1 & V9 & V22 & V11 & V24 & V1 & V14 \\
\cline { 2 - 8 } & 0 & $\mathrm{~V} 0$ & $\mathrm{~V} 26$ & $\mathrm{~V} 0$ & $\mathrm{~V} 26$ & $\mathrm{~V} 0$ & $\mathrm{~V} 26$ \\
\cline { 2 - 8 } & -1 & $\mathrm{~V} 6$ & $\mathrm{~V} 18$ & $\mathrm{~V} 8$ & $\mathrm{~V} 20$ & $\mathrm{~V} 10$ & $\mathrm{~V} 22$ \\
\hline \multirow{2}{*}{0} & 1 & $\mathrm{~V} 11$ & $\mathrm{~V} 24$ & $\mathrm{~V} 1$ & $\mathrm{~V} 14$ & $\mathrm{~V} 3$ & $\mathrm{~V} 16$ \\
\cline { 2 - 8 } & 0 & $\mathrm{~V} 26$ & $\mathrm{~V} 0$ & $\mathrm{~V} 26$ & $\mathrm{~V} 0$ & $\mathrm{~V} 26$ & $\mathrm{~V} 0$ \\
\cline { 2 - 8 } & -1 & $\mathrm{~V} 4$ & $\mathrm{~V} 16$ & $\mathrm{~V} 6$ & $\mathrm{~V} 18$ & $\mathrm{~V} 8$ & $\mathrm{~V} 20$ \\
\hline
\end{tabular}

\section{DTC Method 4}

DTC method 4 comes under the category of DTC scheme II which is different in terms of the number of sectors used and the techniques used in switching table formation. In this scheme, all of the voltage vectors $(\mathrm{L}, \mathrm{M}, \mathrm{S}, \mathrm{Z})$ are used to form the switching table.

\section{Simulation AND RESUlts}

MATLAB / Simulink is used to perform the simulation for the proposed DTC methods and the classical DTC method. The machine parameters used in this paper are the same as those used in literature [26] and [28]. In this paper, the simulation results of the classical DTC, DTC method 1, DTC method 2, DTC method 3 and DTC method 4 are presented. For all of the methods, the performance analysis was carried out on different aspects like the performance at different operating points and performances during external load disturbances.
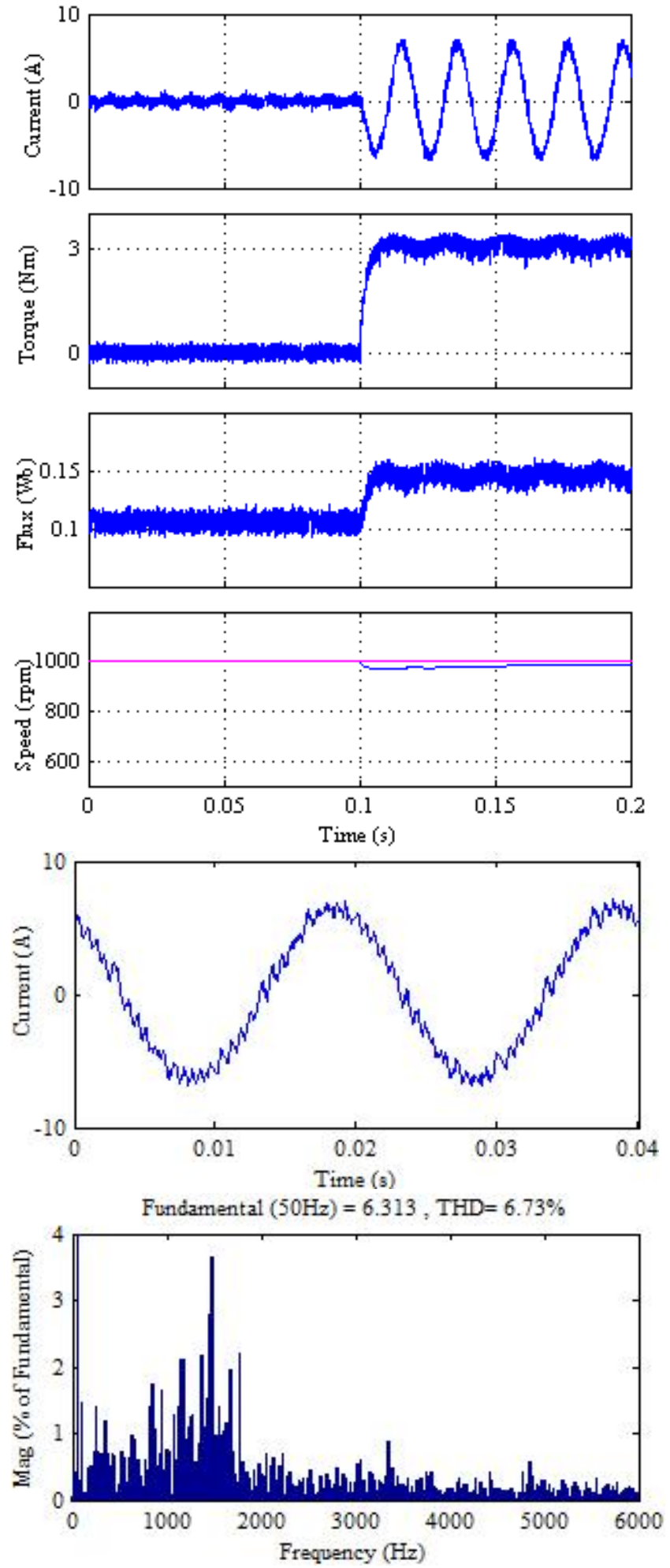

Fig. 3. Response of classical DTC at $1000 \mathrm{rpm}$ with external load of $3 \mathrm{Nm}$.

\section{A. Comparative Study with Existing Work}

First, the classical DTC will be carried out to show the effectiveness of the proposed DTC methods. The proposed methods are also compared with existing methods reported in [26] and [28]. The switching table used in this paper is 
different from those used in [26] and [28] and it is developed based on Table I.

Fig. 3 to Fig. 7 presents the responses at 1000 rpm with an external load of $3 \mathrm{Nm}$ applied at $0.1 \mathrm{~s}$ for the classical DTC and all of the proposed DTC methods. From top to bottom, the waveforms are the stator current, torque, flux, rotor speed and harmonic analysis of the stator current, respectively. Form Table VI, it can be seen that the torque ripple in all of the proposed DTC methods are smaller than the torque ripple in the classical DTC. For simplicity, the proposed DTC methods are classified into two categories. The first DTC scheme (DTC method 1, DTC method 2 and DTC method 3) using two voltage vectors in the switching table, and the second DTC scheme (DTC method 4) using three voltage vectors to form the switching table. It can be seen that the torque ripple of DTC method 1 is slightly less than that of the classical DTC. This is due to the fact that both methods utilize two voltage vectors, such as large and zero voltage vectors (see Table 1), in their switching table. The slight reduction in the torque ripple is due to the effective voltage vector used in the switching table. The two voltage vector is also used in DTC method 2 and DTC method 3. Compared with DTC method 1, there is lesser torque ripple reduction in DTC method 2, whereas there is a significant reduction in DTC method 3. However, DTC method 4 provides a much lower torque ripple when compared with the other proposed DTC methods. From the above discussion, it can be seen that the four voltage vector based DTC can significantly reduces the torque ripple when compared to the classical DTC and the other existing DTC methods (refer Table VI). Of the two voltage vector based DTCs (DTC method 1, DTC method 2 and DTC method 3) DTC method 3 exhibits the best performance. The key point in this DTC is that the small voltage vectors contribute to torque in the same direction and produce a smaller torque ripple when compared to the classical DTC, DTC method 1 and DTC method 2. One more important observation is that if a small voltage vector is included in the combination, less torque ripple is produced.

Table VI provides a quantitative comparison of the proposed DTC methods with all of the other DTC methods. The proposed DTC methods produces lesser torque ripple when compared to classical DTC and other existing methods [26] and [28]. When compared with the existing DTC methods [26] and [28], the proposed DTC methods 3 and 4 provide lesser torque ripple. The Root Mean Square (RMS) torque ripple is followed in the literature [26], [28] and it is followed in this paper as well. The proposed DTC 3 results in a torque ripple that is only $54.49 \%, 89.36 \%$ and $98.38 \%$ of that of the classical DTC, literature [26] and [28], respectively. Similarly, the proposed DTC method 4 produces torque ripple that is only $55.24 \%, 90.59 \%$ and $99.73 \%$ of that of the classical DTC, literature [26] and [28], respectively.
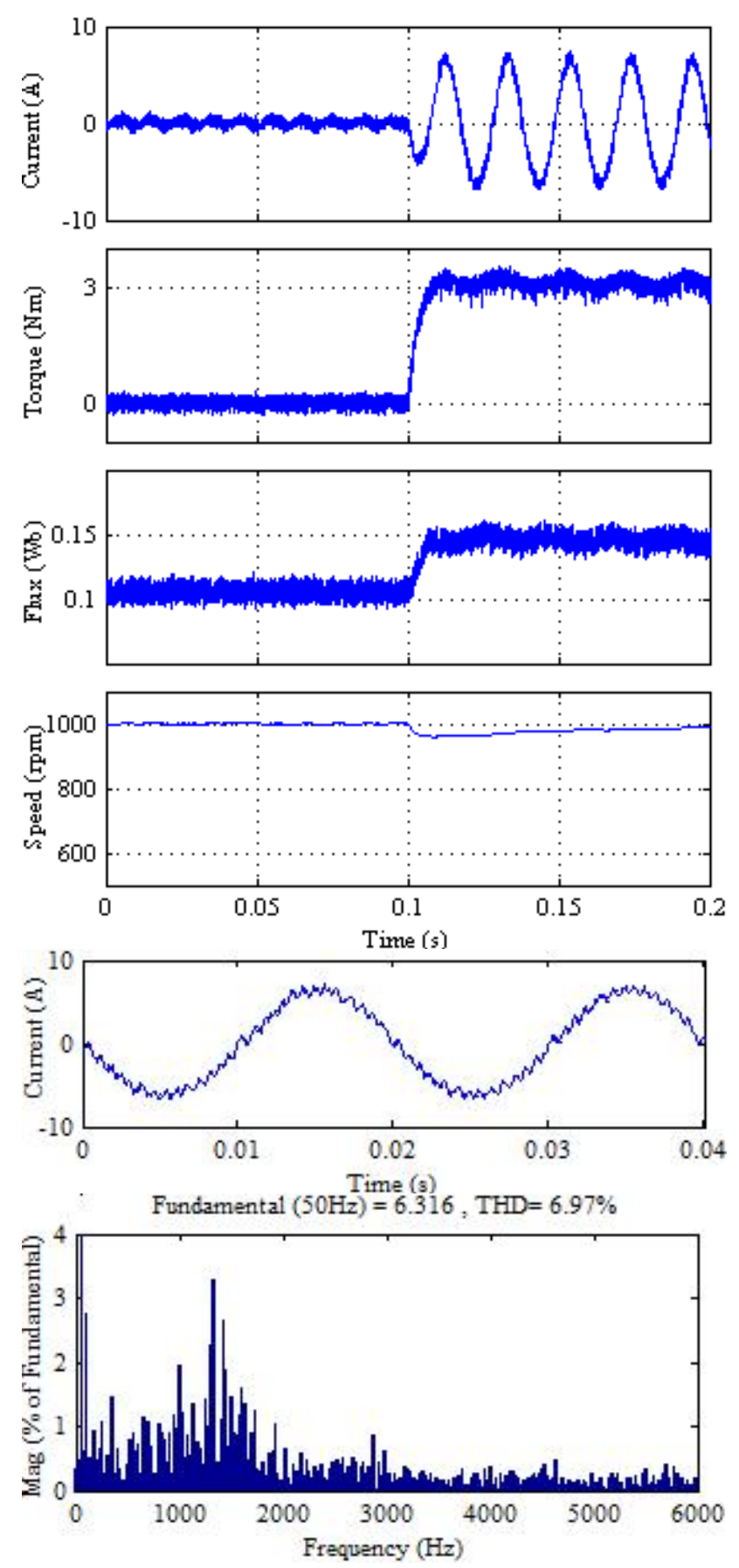

Fig. 4. Response of DTC method 1 at $1000 \mathrm{rpm}$ with external load of $3 \mathrm{Nm}$.

The average commutation frequency is calculated using the formula, $f_{a v}=\mathrm{N} / \mathrm{K} / 0.05$, where, $\mathrm{N}$ is the total commutation instants of all the legs of the inverter used in the DTC methods during a fixed period, e.g., $0.05 \mathrm{~s}$ in this paper, and $\mathrm{K}$ is the switch number. DTC method 3 and DTC method 4 provide lesser average commutation frequency when compared to the classical DTC and the results reported in literature [26] and [28]. The proposed DTC methods 3 and 4 exhibit better performance in terms of torque ripple and 

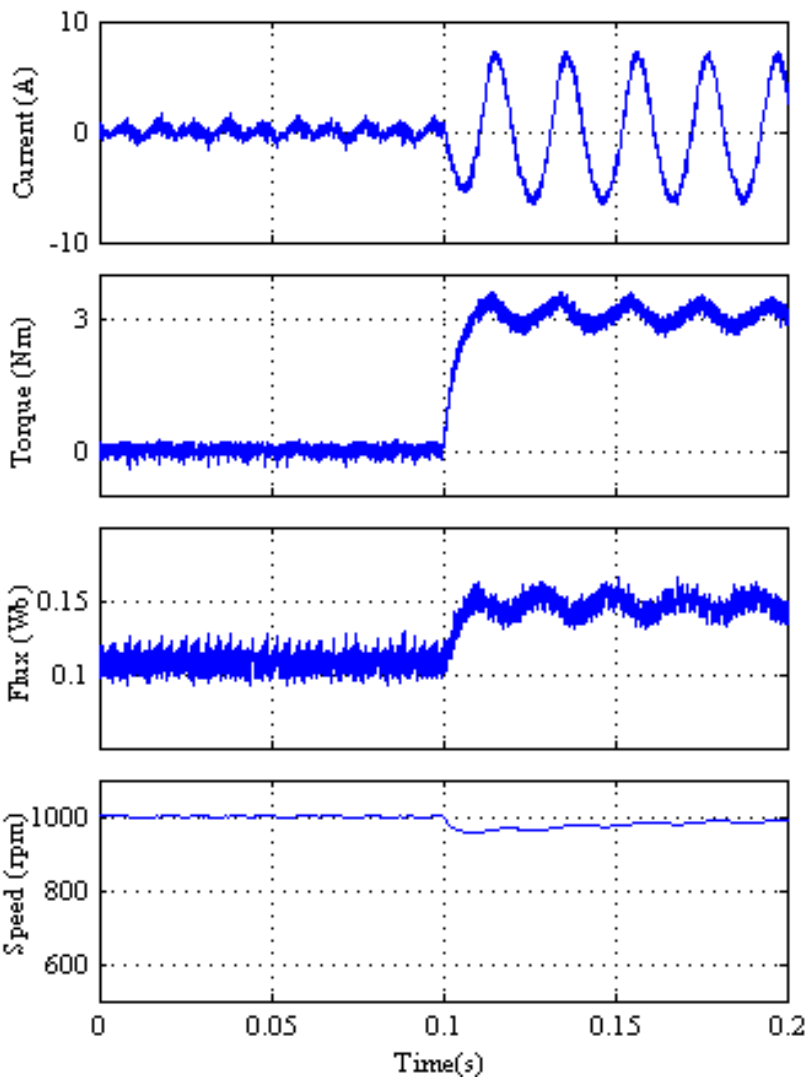

Fundamental $(50 \mathrm{~Hz})=6.311, \mathrm{THD}=5.70 \%$

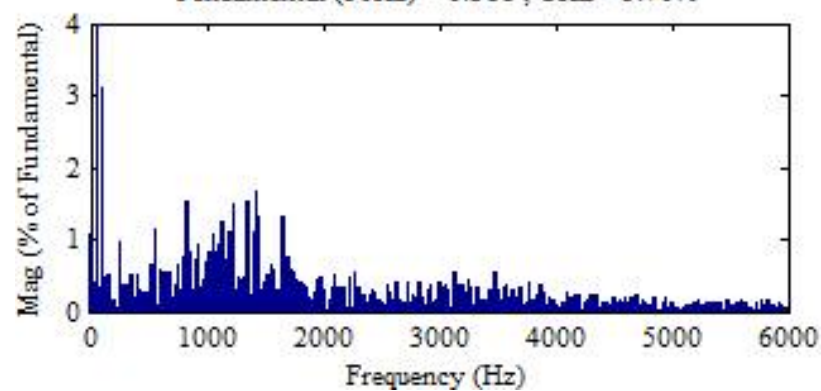

Fig. 5. Response of DTC method 2 at $1000 \mathrm{rpm}$ with external load of $3 \mathrm{Nm}$.

average commutation frequency, $f_{a v}$. The average commutation frequency of DTC method 3 is $1.63 \mathrm{kHz}$ and for DTC method 4 it is $3.09 \mathrm{kHz}$, which is less than in literature [26] and [28].

The proposed DTC method 3 has an average commutation frequency, $f_{a v}$ that is only $30.41 \%, 36.96 \%$ and $50.62 \%$ of that of the classical DTC, and the existing DTC methods available in the literature [26] and [28], respectively. However, the average commutation frequency of the proposed DTC method 4 is $3.09 \mathrm{kHz}$, which is less than that obtained papers [26] and [28]. The proposed DTC method 4 has an average commutation frequency, $f_{a v}$ that is only $57.65 \%, 70.07 \%$ and $95.96 \%$ of that of the classical DTC, the existing DTC methods available in the literature [26] and
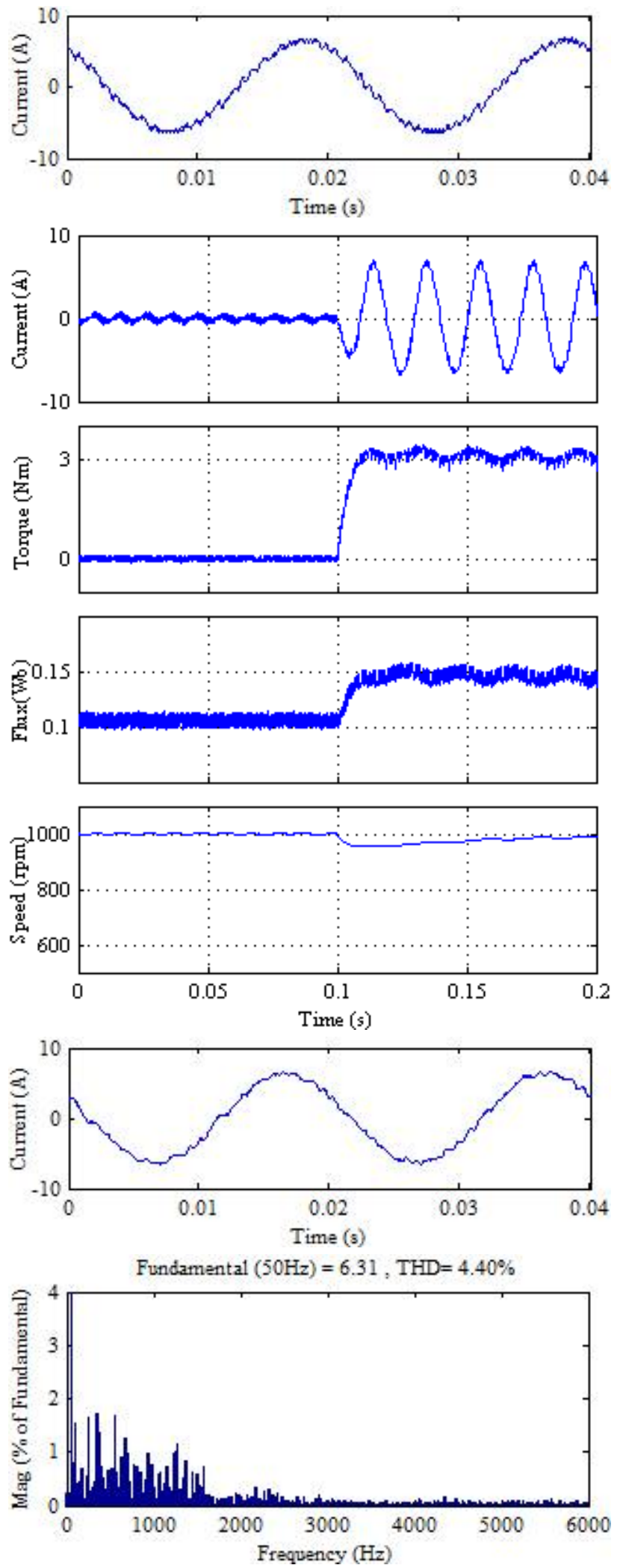

Fig. 6. Response of DTC method 3 at $1000 \mathrm{rpm}$ with external load of $3 \mathrm{Nm}$.

[28], respectively. This validates the superiority of the proposed DTC methods. 

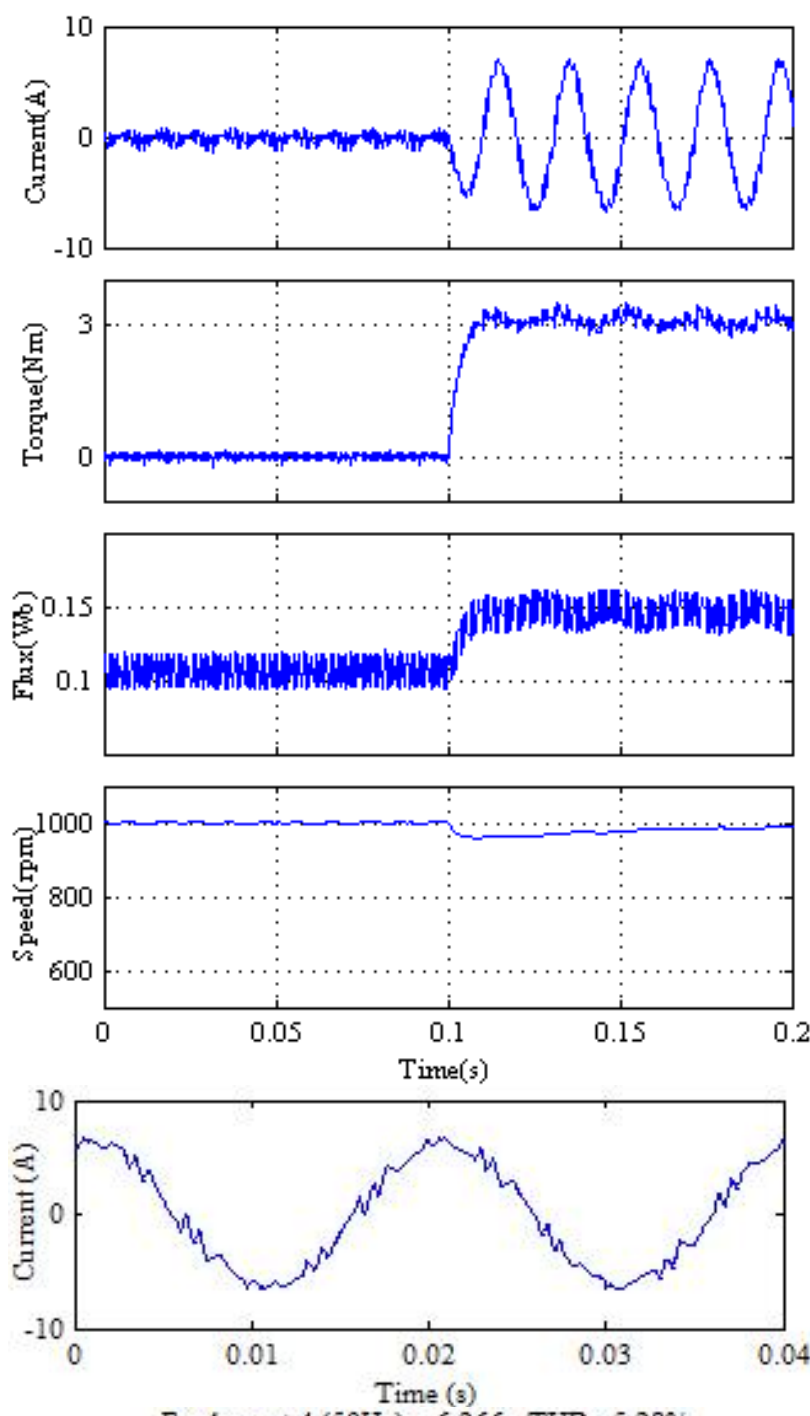

Fundamental $(50 \mathrm{~Hz})=6.266, \mathrm{THD}=5.28 \%$

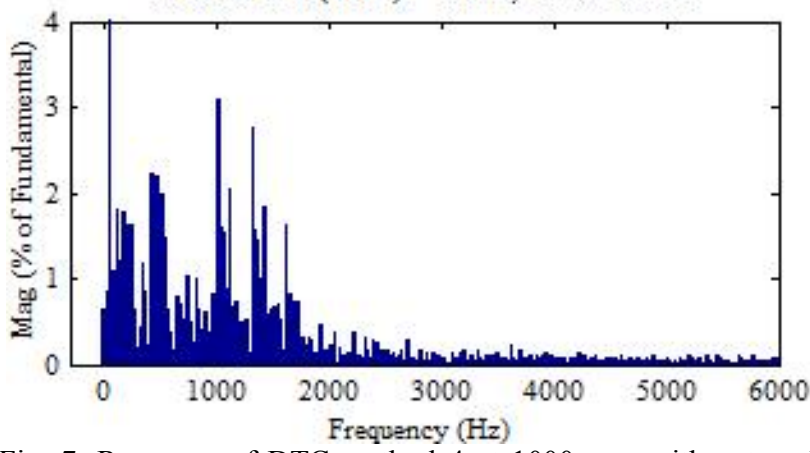

Fig. 7. Response of DTC method 4 at $1000 \mathrm{rpm}$ with external load of $3 \mathrm{Nm}$.

It can be seen that the current waveform is more sinusoidal and has less harmonic content with the proposed DTC methods when compared with existing methods. The Total Harmonic Distortion (THD) is calculated up to $6000 \mathrm{~Hz}$. The dominant harmonics between $2000 \mathrm{~Hz}$ and $4000 \mathrm{~Hz}$ in the proposed DTC methods 3 and 4 are much lesser when compared to the other proposed methods and the classical DTC method. It can be seen that the stator current THD of
TABLE VI

Quantitative Comparison of the Proposed DTC Methods WITH EXISTING DTC METHODS

\begin{tabular}{|c|c|c|c|c|}
\hline Method & $f_{a v}$ & $\begin{array}{c}\Phi_{\text {ripple }} \\
(\mathrm{Hz})\end{array}$ & $\begin{array}{c}T_{\text {ripple }} \\
(\mathrm{Nm})\end{array}$ & $\begin{array}{c}\text { THD } \\
\text { of Stator } \\
\text { Current }\end{array}$ \\
\hline $\begin{array}{c}\text { Classical } \\
\text { DTC }\end{array}$ & $5.36 \mathrm{k}$ & 0.0066 & 0.2004 & $6.73 \%$ \\
\hline $\begin{array}{c}\text { Y. Zhang } \\
\text { et al.[ 26] }\end{array}$ & $4.41 \mathrm{k}$ & 0.0043 & 0.1222 & $5.85 \%$ \\
\hline $\begin{array}{c}\text { Y. Zhang } \\
\text { et al. [28] }\end{array}$ & $3.22 \mathrm{k}$ & 0.0017 & 0.1110 & $4.67 \%$ \\
\hline $\begin{array}{c}\text { DTC } \\
\text { method 1 }\end{array}$ & $4.99 \mathrm{k}$ & 0.0064 & 0.1956 & $6.97 \%$ \\
\hline $\begin{array}{c}\text { DTC } \\
\text { method 2 }\end{array}$ & $4.68 \mathrm{k}$ & 0.0063 & 0.1563 & $5.70 \%$ \\
\hline $\begin{array}{c}\text { DTC } \\
\text { method 3 }\end{array}$ & $1.63 \mathrm{k}$ & 0.0048 & 0.1092 & $4.40 \%$ \\
\hline $\begin{array}{c}\text { DTC } \\
\text { method 4 }\end{array}$ & $3.09 \mathrm{k}$ & 0.0086 & 0.1107 & $5.28 \%$ \\
\hline
\end{tabular}

DTC method 3 is $4.40 \%$, which is much lower than the $5.85 \%$ and $4.67 \%$ of the existing DTC methods available in papers [26] and [28].

In terms of the stator current THD, DTC method 3 exhibits better performance. However, in addition to DTC method 3, DTC method 4 also provides lesser stator current THD when compared to the classical DTC and the existing literature [26]. Fig. 13 demonstrates the effectiveness of the proposed DTC methods over the existing DTC methods. Similar conclusions are made for various operating point of the classical DTC and the proposed DTC methods with no load for an example. Due to page constraints, the waveform results are not listed here. However, a quantitative comparisons of the classical and proposed DTC methods are shown in Fig. 13. This comparison is useful to indicate to the end users the various applications that today require torque control.

\section{B. Results at $10 \%$ of the Rated speed}

The proposed DTC methods are analyzed at different operating points. In Fig. 8 the operating point is considered at $200 \mathrm{rpm}(10 \%$ of the rated speed) without a load as an example. Fig. 8 shows the flux and torque responses for the classical DTC, DTC method 1, DTC method 2, DTC method 3 and DTC method 4, respectively. From top to bottom, the responses shown in Fig. 8 are the classical DTC, DTC method 1, DTC method 2, DTC method 3 and DTC method 4, respectively. The flux response is on the left and torque response is on the right.

It can be seen that at an operating point of $200 \mathrm{rpm}$, DTC method 1 gives almost same performance as the classical DTC 

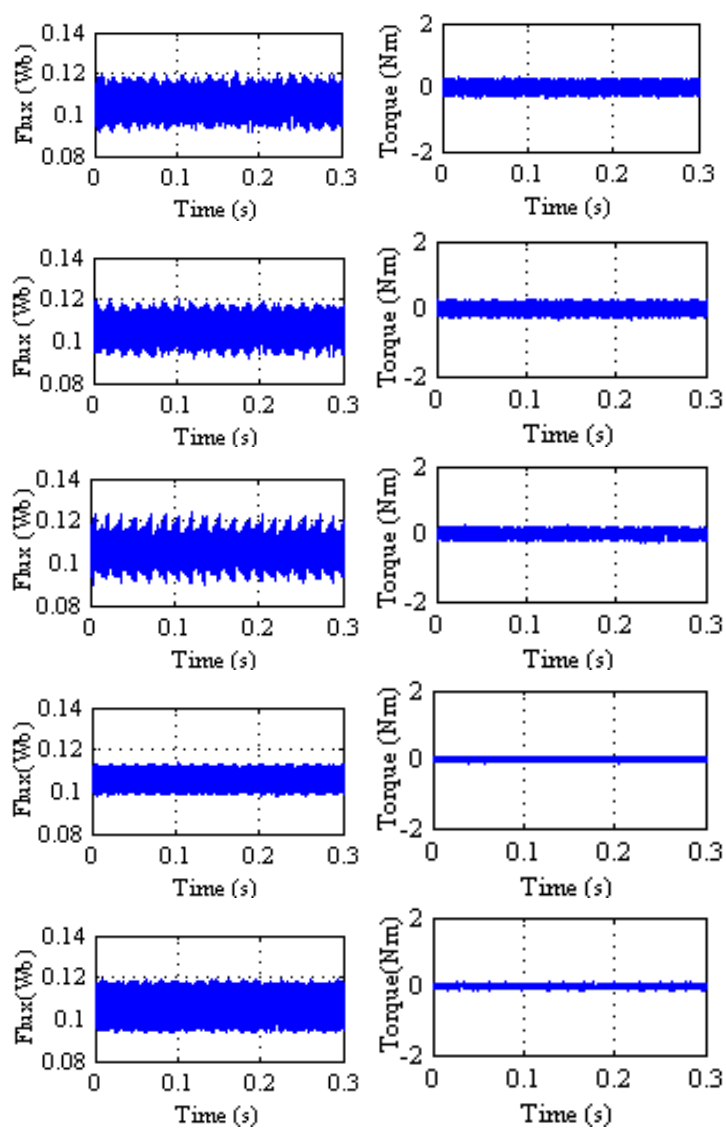

Fig. 8. Steady state response at $200 \mathrm{rpm}(10 \%$ of the rated speed) for classical DTC, DTC method 1, DTC method 2, DTC method 3 and DTC method 4.

because their switching patterns are similar. However, DTC method 2 gives less torque ripple when compared to the classical DTC and DTC method 1, but gives instantaneous spikes in the flux. The main drawback of the DTC drive is increased torque ripple at lower speeds. As a result, this analysis provides an important conclusion. It can be concluded that DTC method 3 presents the best overall performance among the four proposed DTC methods and the classical DTC.

\section{Results at $25 \%$ of the Rated Speed}

At this operating point, in the view of the flux and torque ripples, DTC method 3 exhibits the best performance followed by DTC method 4, DTC method 2, DTC method 1 and the classical DTC. The ripples in the flux and torque waveform are also significantly diminished in DTC method 3 when compared to other methods proposed in this paper. This can be observed from Fig. 9.

\section{Results at $50 \%$ of the Rated speed}

As shown in Fig. 10 the high ripples and distortion in the flux and torque waveform can be noticed in all of the methods.
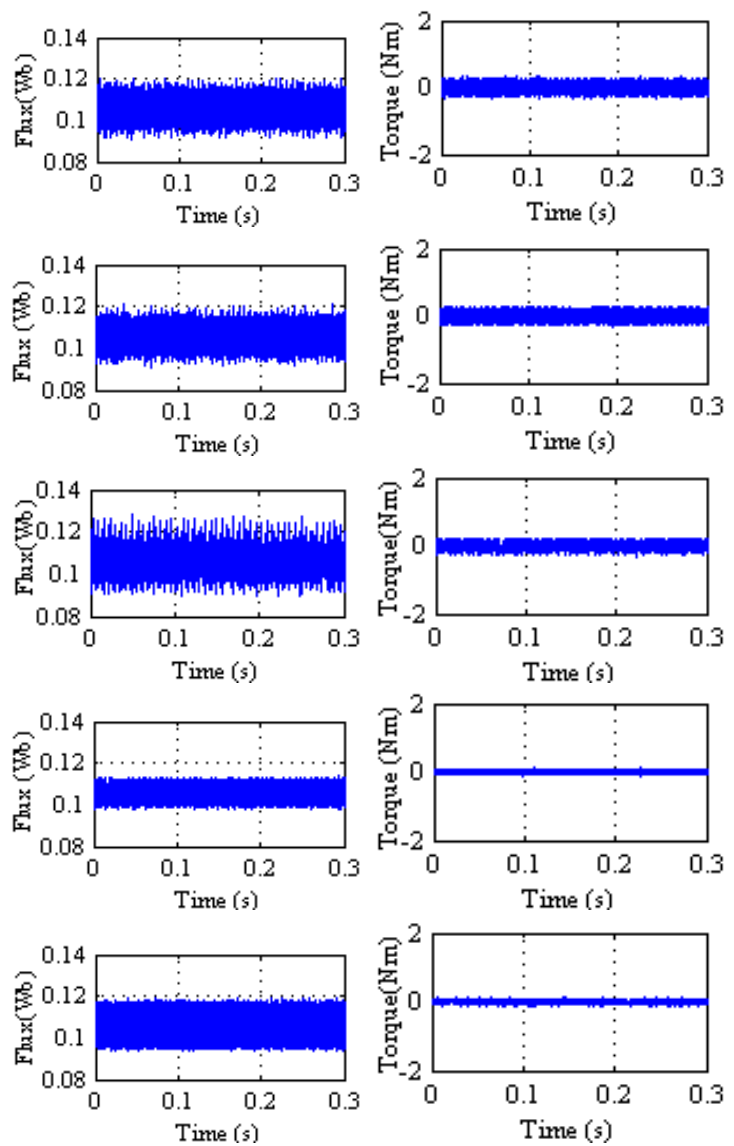

Fig. 9. Steady state response at $500 \mathrm{rpm}(25 \%$ of the rated speed) for classical DTC, DTC method 1, DTC method 2, DTC method 3 and DTC method.

However, a remarkable reduction in the torque ripple can be observed in DTC method 3. DTC method 3 and DTC method 4 provide similar torque ripples, but instantaneous spikes are noticed in the torque response of DTC method 4.

\section{E. Results at $75 \%$ of the Rated speed}

DTC method 1 almost imitates the classical DTC. DTC method 2 presents the lowest torque ripple among the other methods. According to the switching table of this method, at any point in time, the inverter provides half voltages for two lines and zero voltage for one line. This voltage is not sufficient to rotate the rotor at this speed. DTC method 3 gives satisfactory operation up to $70 \%$ of the rated speed. However, DTC method 4 provides lesser torque ripple when compared to all of the other methods.

\section{F. Results at $100 \%$ of the Rated speed}

It is found that there is no significant improvement in DTC method 1 when compared to the classical DTC. Large vectors are considered in both the classical DTC and DTC method 1. According to equation (7) this leads large torque ripples. At 

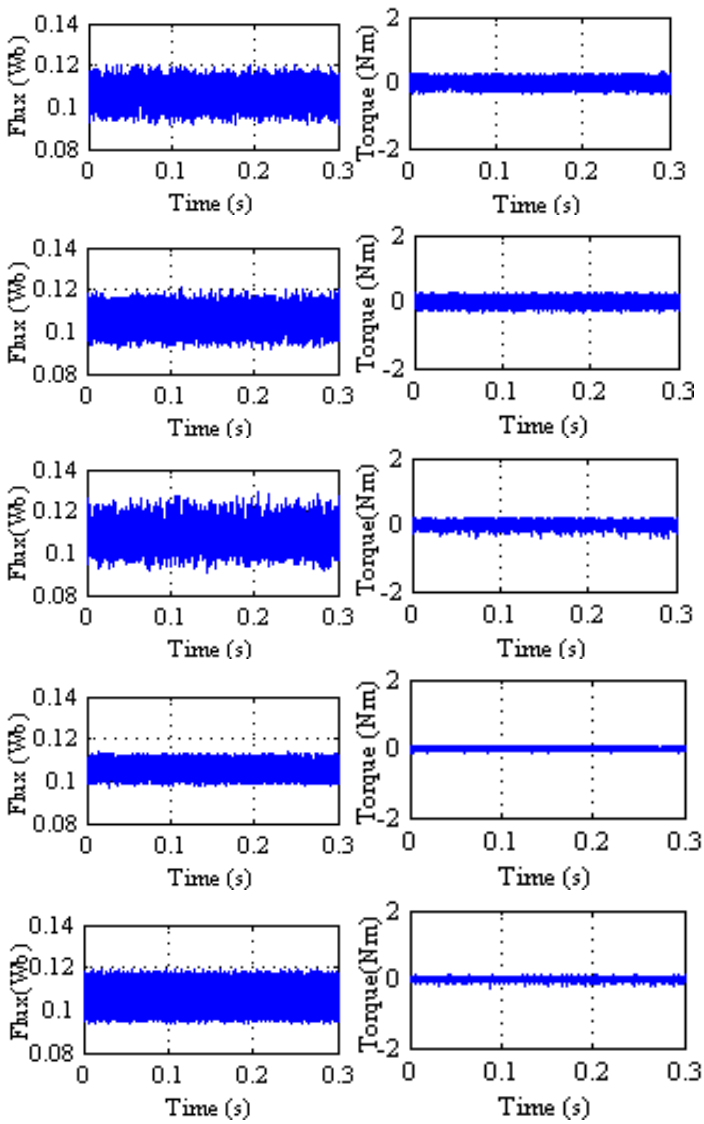

Fig. 10. Steady state response at $1000 \mathrm{rpm}(50 \%$ of the rated speed) for classical DTC, DTC method 1, DTC method 2, DTC method 3 and DTC method 4.
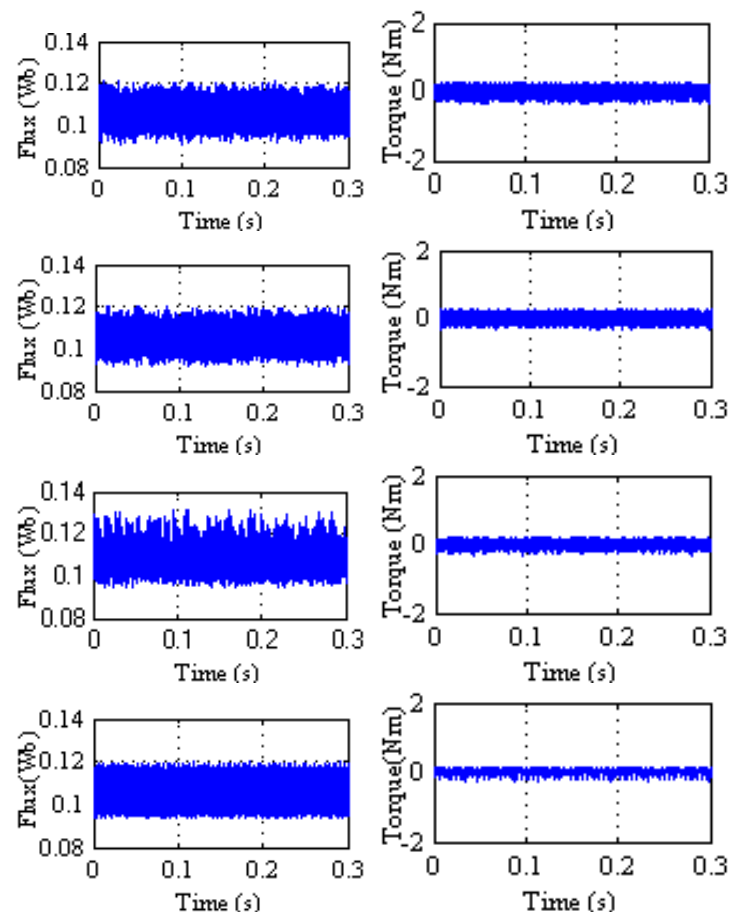

Fig. 11. Steady state response at $1500 \mathrm{rpm}(75 \%$ of the rated speed) for classical DTC, DTC method 1, DTC method 2 and DTC method 4.
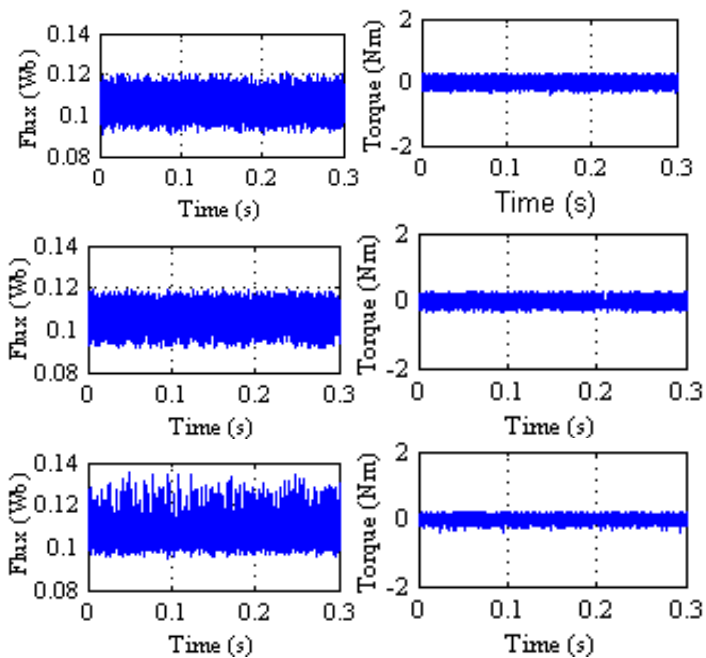

Fig. 12. Steady state response at $2000 \mathrm{rpm}(100 \%$ of the rated speed) for classical DTC, DTC method 1 and DTC method 2.

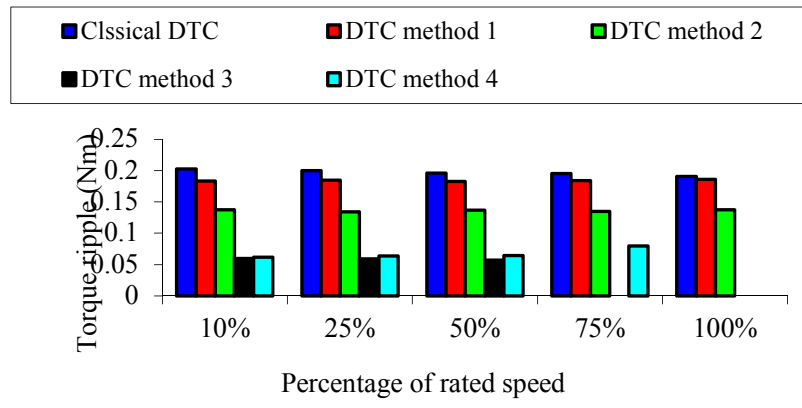

Fig. 13. Comparison of the torque ripple for classical DTC, DTC method 1, DTC method 2, DTC method 3 and DTC method 4.

the same time, DTC method 2 presents lesser torque ripple when compared to the other methods. Nevertheless, DTC method 3 is not able to trace the reference target.

\section{G. Response to External load disturbances}

The responses to external disturbances are shown in Fig. 14 (a) - (e) for the classical DTC, DTC method 1, DTC method 2, DTC method 3 and DTC method 4, respectively. The motor is operated at a the steady state with $2.5 \mathrm{Nm}$ and $50 \%$ of the rated speed. Then the load is suddenly removed in order to check the disturbance rejection capability of both the classical and the proposed DTC methods.

In a very short period, the motor speed returns to its original speed due to its fast torque response. It is observed that there are about $3 \%$ peak speed increases for all the proposed DTC methods 1, 2, 3 and 4, whereas it is about $2.5 \%$ for the classical DTC method when the load is suddenly removed. However, almost all of the DTC methods including the classical DTC method take the same amount of time to reach their original speed after the load is removed. 

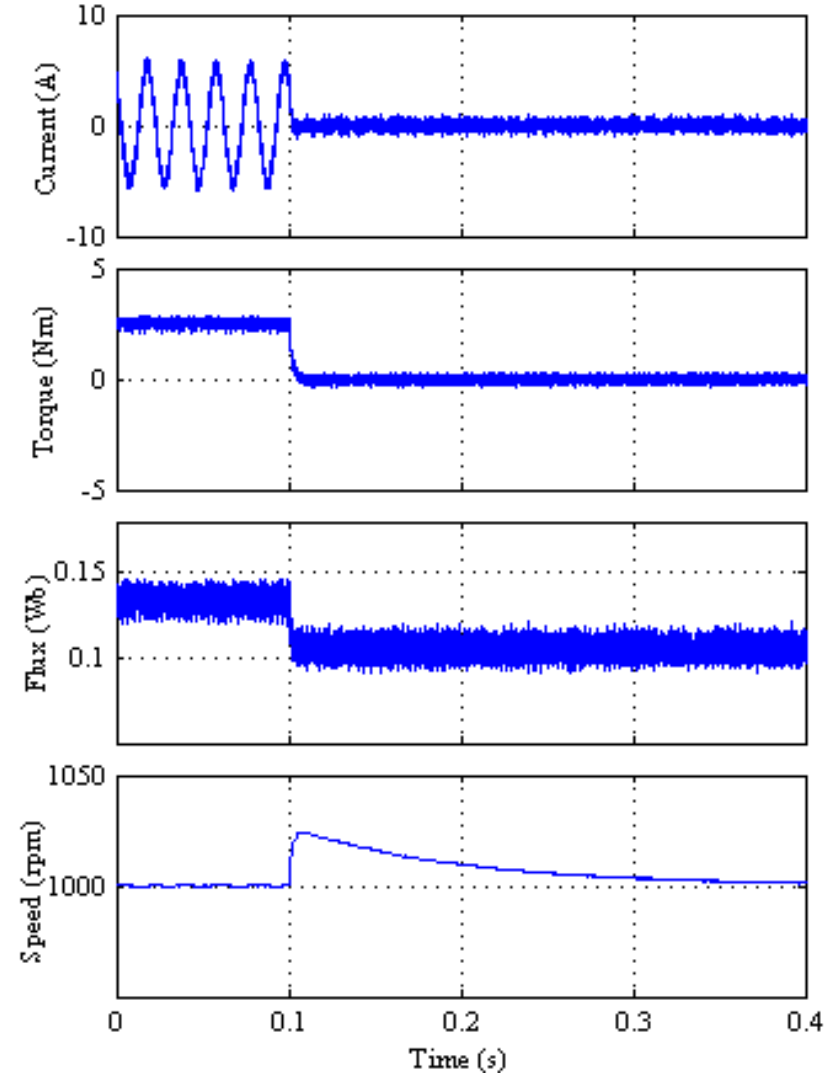

(a)
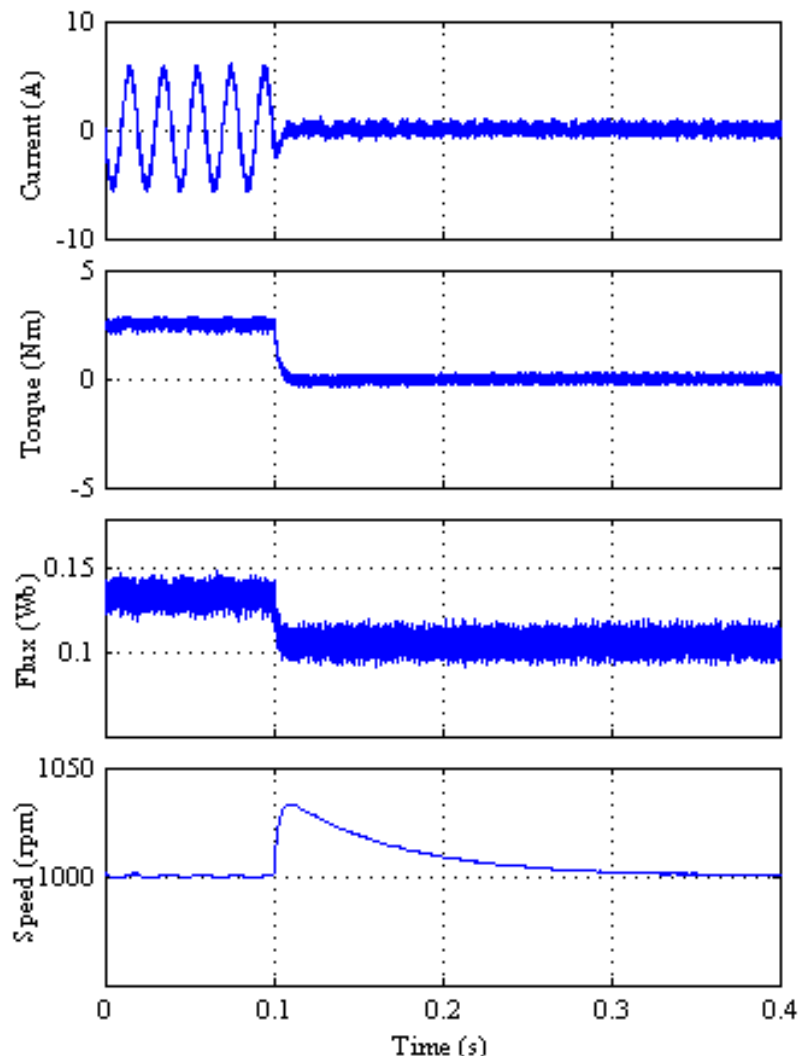

(b)
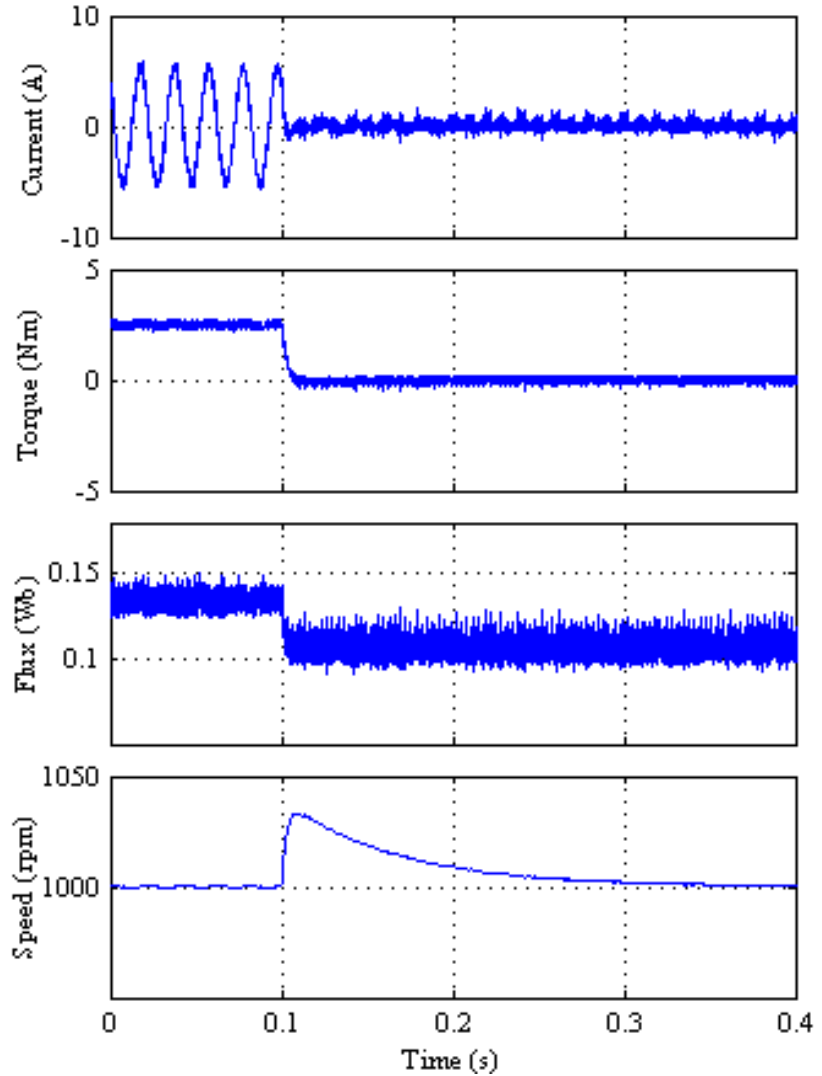

(c)
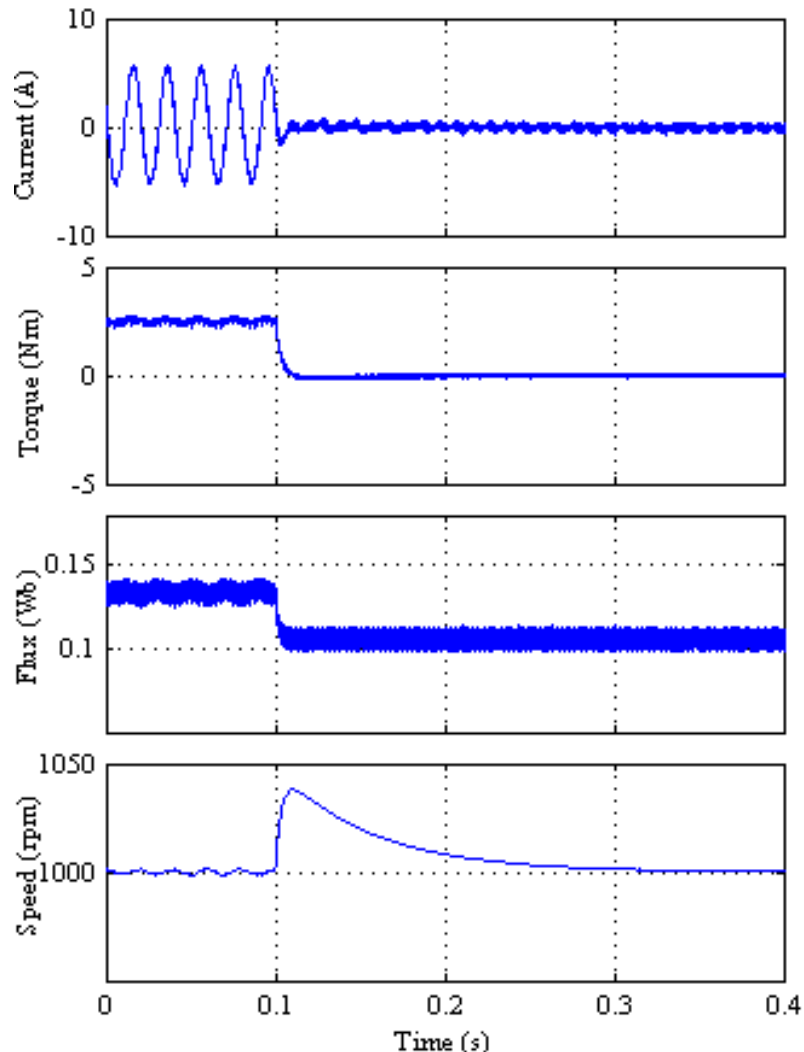

(d) 


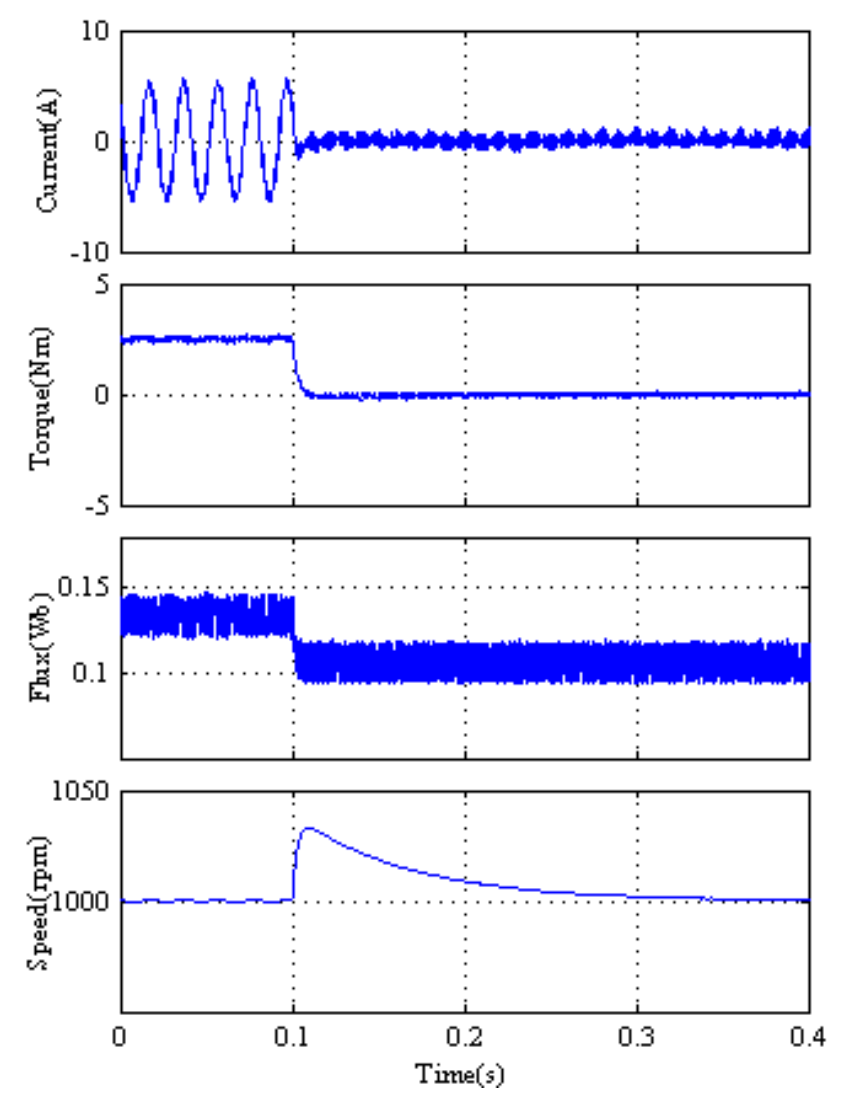

(e)

Fig. 14. Response to external load disturbance for: (a) Classical DTC; (b) DTC method 1; (c) DTC method 2; (d) DTC method 3; (e) DTC method 4.

This comparison shows that all of the proposed DTC methods exhibiting fast response of the torque when compared to the classical DTC. Even though the peak speed increases about $3 \%$, it takes less time to reach its steady state whereas the classical DTC takes same time to reach it from its $2.5 \%$ peak speed. However, the classical DTC, DTC method 1 and DTC method 2 exhibit the best performance at the cost of a larger torque ripple whereas DTC method 3 provides lesser torque ripple and better performance in terms of disturbance rejection.

\section{H. Response during Start-up}

In addition to the disturbance rejection characteristics, the startup characteristics are also analyzed in this paper. The responses during start-up can be seen from the Fig. 15 (a)-(e) for the classical and all of the other proposed DTC methods. Fig. 15 (a)-(e) shows the startup response without a load from zero rpm to $1000 \mathrm{rpm}$ for all of the DTC methods. In all of the figures, the commending speed is marked in red and the actual speed is in blue. The zoomed response of the speed characteristics is also inserted to show the actual picture. According to the DTC principle, the motor should satisfy load requirements without any change in speed.
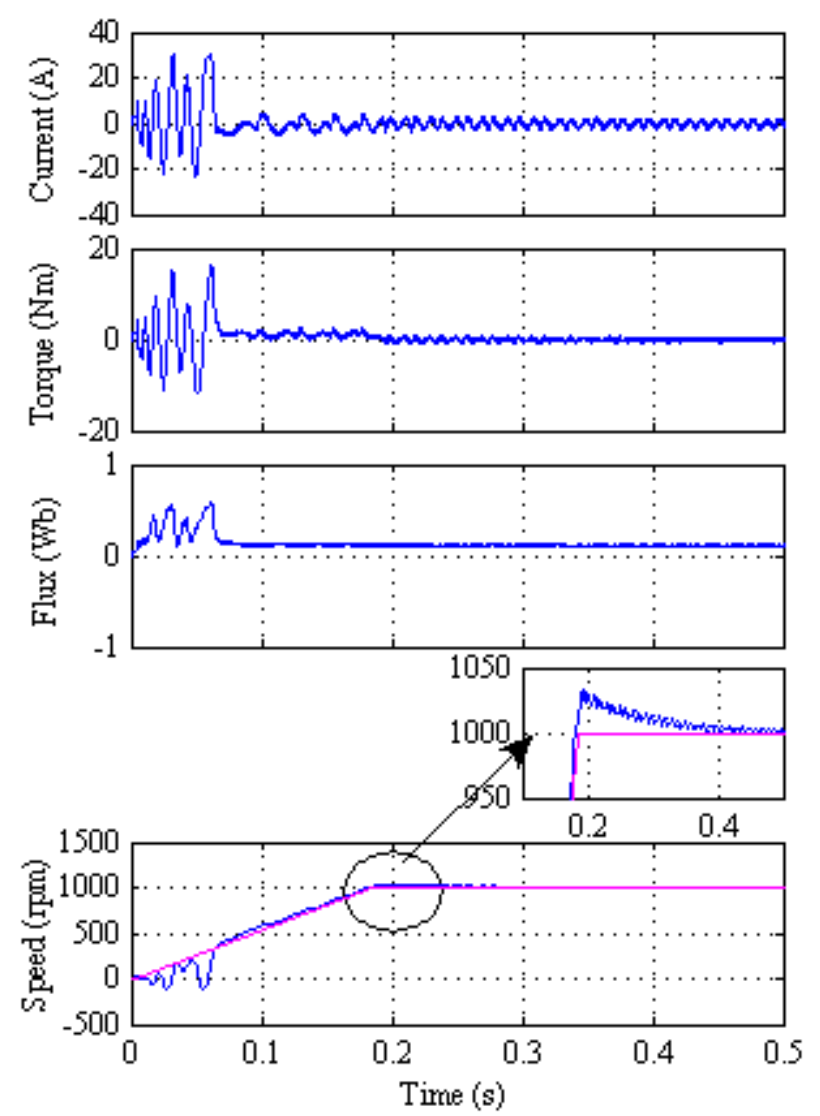

(a)
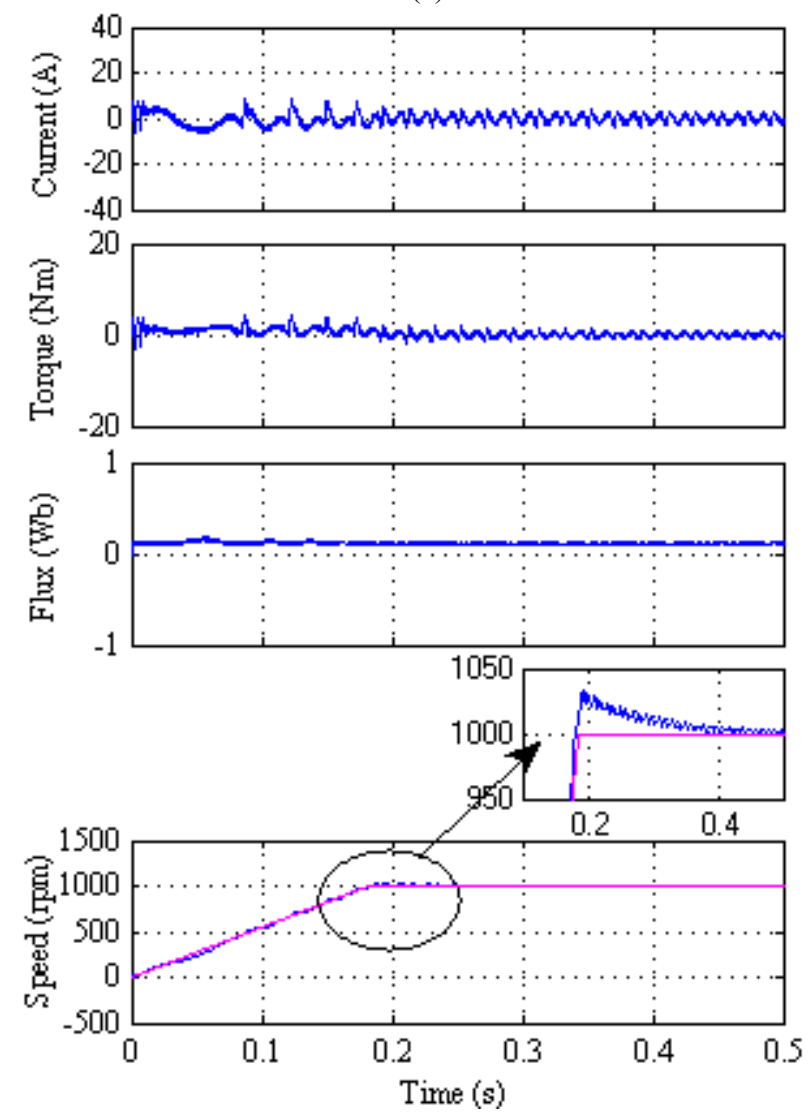

(b) 

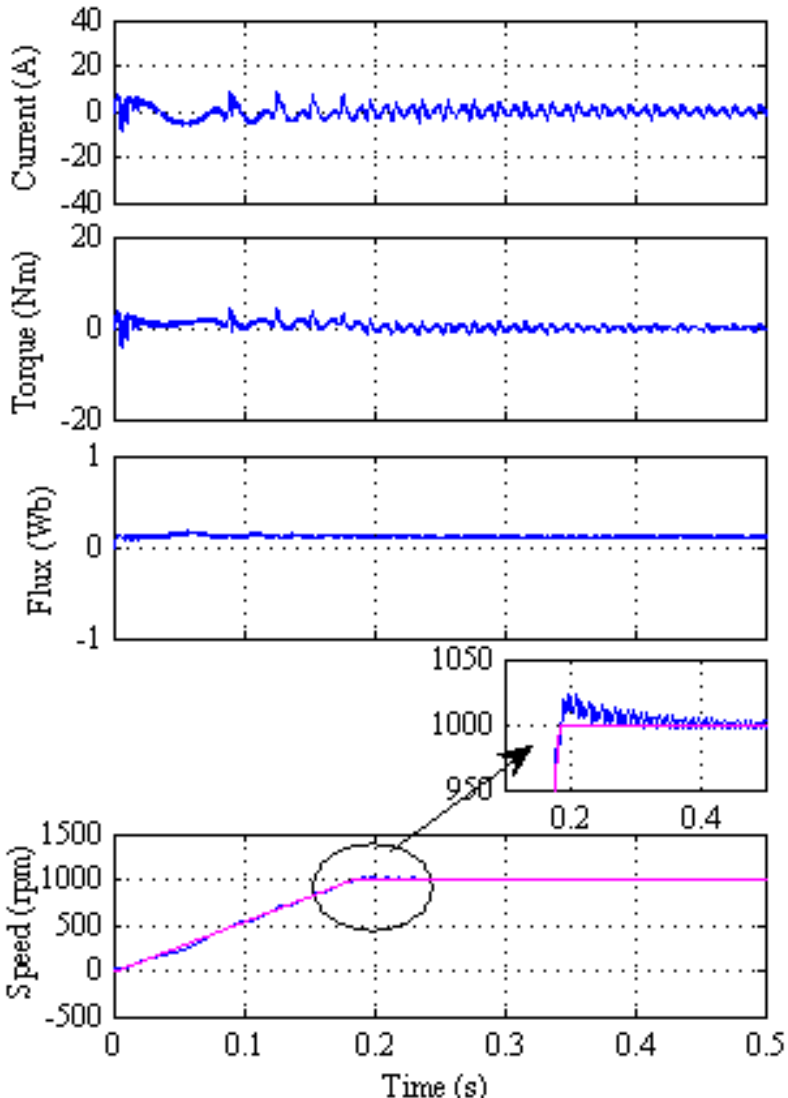

(c)
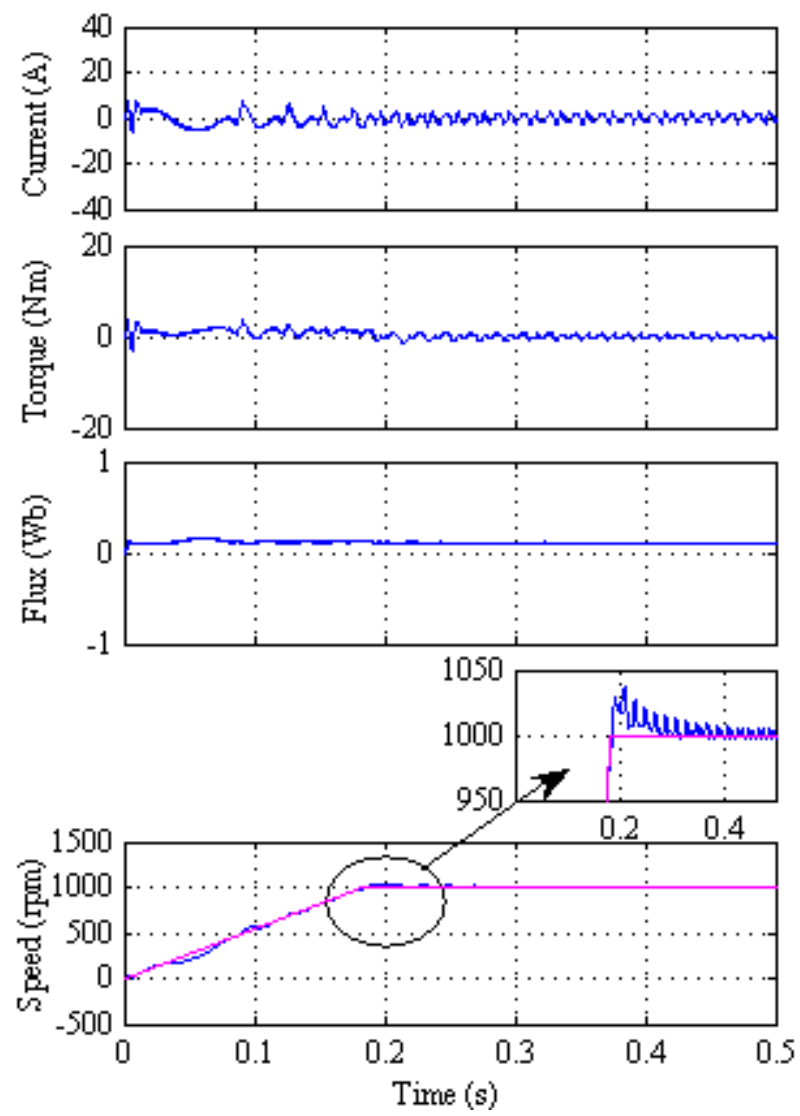

(d)
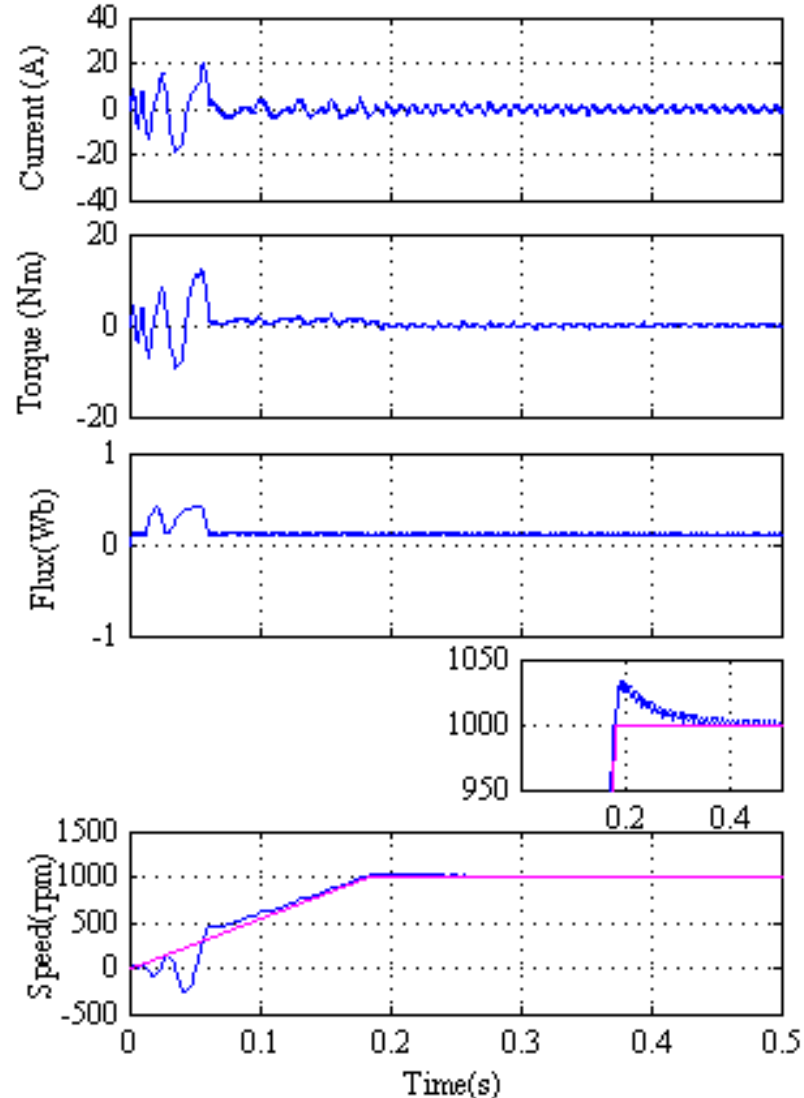

(e)

Fig. 15. Response during start-up : (a) Classical DTC; (b) DTC method 1; (c) DTC method 2; (d) DTC method 3; (e) DTC method 4 .

Almost all of the DTC methods take about $0.2 \mathrm{~s}$ for the speed to reach its commended value. However, the steady state performance of the proposed DTC methods are greatly improved, even though all of the DTC methods take the same amount of time. The zoomed view of the speed response clearly shows the overshoot in speed. The rise in speed of DTC method 1 and DTC method 2 is smaller than the other DTC methods at the cost of a higher overshoot in speed. From Fig. 15, it can be seen that all of the DTC methods are able to track the commending speed. However, the classical DTC and DTC method 4 have a smaller disturbance at the time of starting. There are $3 \%$ peak speed increases in all of the proposed DTC methods whereas there is a $2.5 \%$ peak speed increase in the classical DTC method, which is similar to the results obtained during external load disturbances. This is also noticed from the view point of the starting current taken by the motor. Except for DTC method 4, the starting inrush current for the proposed DTC methods are less when compared to the classical DTC method. In a similar fashion the ripples in the torque developed by the motor are also greatly reduced in the proposed DTC methods throughout operation. From the above discussions, it can be concluded 


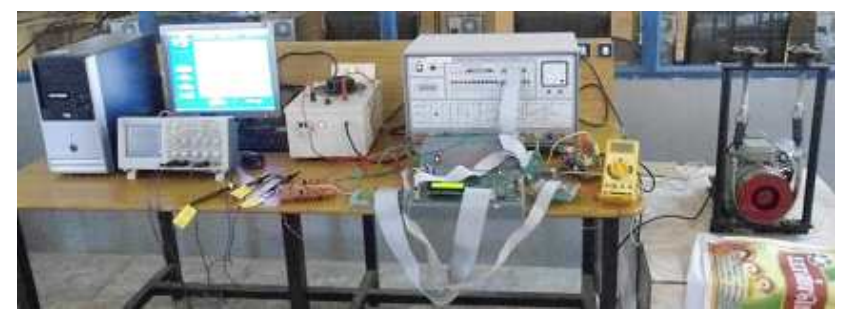

Fig. 16. Snapshot of the Experimental arrangement.

that all of the proposed DTC methods can be suitable for adjustable speed applications.

\section{EXPERIMENTAL RESULTS}

In addition to the simulation results, the proposed DTC method is experimentally tested to verify the effectiveness of the proposed methods. The experimental arrangement of the proposed system is same as that of Fig. 2. A $1 \mathrm{~kW}$ PMSM is used for this experimental verification. Fig. 16 shows the experimental arrangement of the proposed system. The three phase intelligent power module is developed with an insulated gate bipolar transistor, which is used as an inverter. The gating pulses are generated in the SPARTAN 3A / 3A DSP FPGA board and then sent to the inverter. All of the experimental results are taken with help of a Tektronix TDS 2004B digital storage oscilloscope. Sample experimental results for the proposed DTC method 3 are shown in Fig. 17, because this method provides the best results among all of DTC methods discussed in this paper.

Various experimental results were taken such as current, torque and speed at various operating points with and without a load. Experimental results were also take to evaluate robustness against external load disturbances. Fig. 17 shows the response of the proposed DTC method 3 with a load of 3 $\mathrm{Nm}$ and a speed of $1000 \mathrm{rpm}$. The current drawn by the motor is almost sinusoidal as can be seen from Fig. 17 (b). Fig. 17 (c) shows a step change in the torque from no load torque to $3 \mathrm{Nm}$ load torque. From the experimental results, the RMS torque ripple of the proposed DTC method 3 is $0.1463 \mathrm{Nm}$ whereas for the same method $0.1092 \mathrm{Nm}$ is obtained from the simulation. The responses to external load disturbances can be seen in Fig. 18. The increment in the current magnitude can be seen in Fig. 18. At the same time there is no observable reduction in the speed. The experimental setup still demands improvements in the area of digital implementation. If this is achieved the proposed DTC method is supposed to have performance similar to that obtained in the simulation.

\section{IMPORTANT OBSERVATIONS}

Remark 1: The first observation is the influence the number

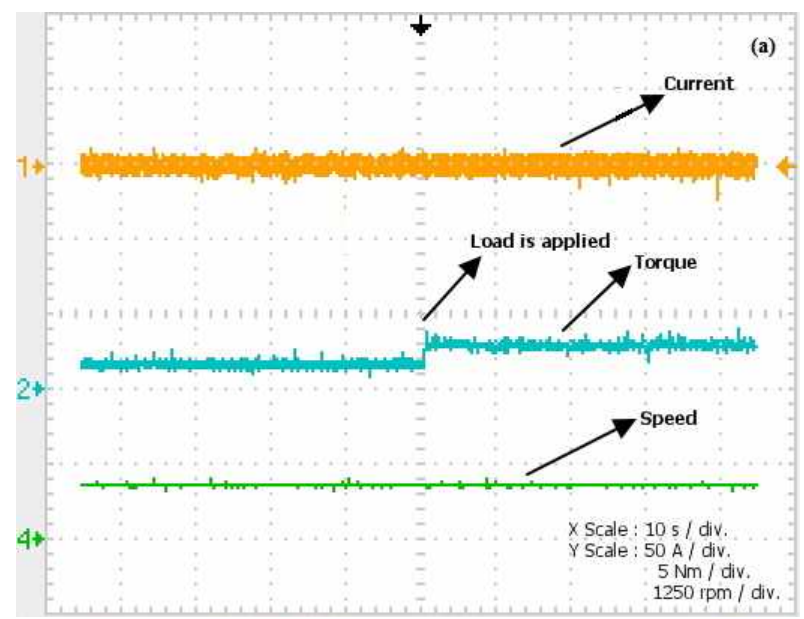

(a)

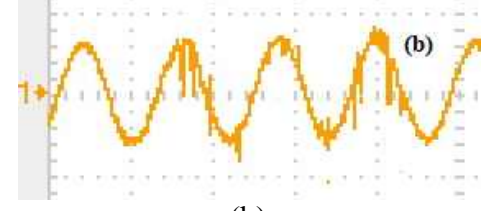

(b)

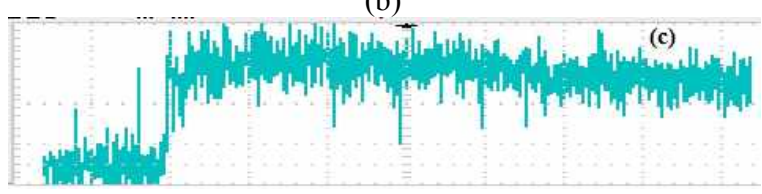

(c)

Fig. 17. Experimental results of the proposed DTC method 3 at $1000 \mathrm{rpm}$ with external load of $3 \mathrm{Nm}$. (a) Current, Torque and speed response. (b) Zoom-in view of current waveform. (c) Zoom-in view of Torque response.

of sectors has on the torque ripple in DTC. Twelve sector DTC is capable of reducing torque ripple, but not by a significant ammount.

Remark 2: A very simple and effective voltage vector combination is proposed in this paper, which can significantly reduce the torque ripple and distortion (THD) in the stator current. All of the proposed DTC methods are capable of reducing torque ripple (Refer to Table VI).

Remark 3: From the analysis, it can be concluded that the number of vectors (two vector based or four vector based) used in the group will not influence on the torque ripple of DTC. At the same time, the type of voltage vector (L, M, S or Z) will affect the torque ripple to a greater extent.

Remark 4: The torque ripple is significantly reduced, if a small voltage vector combines with any other category of voltage vector. The Small-Zero and Large-Medium-Small-Zero voltage vector combinations are identified as effective voltage vector combinations by theoretical and computer simulation analysis.

Remark 5: In this paper, the classical DTC method and all of the proposed DTC methods are comparatively investigated in terms of torque ripple, and disturbance rejection performance during external load disturbance. By an effective voltage 


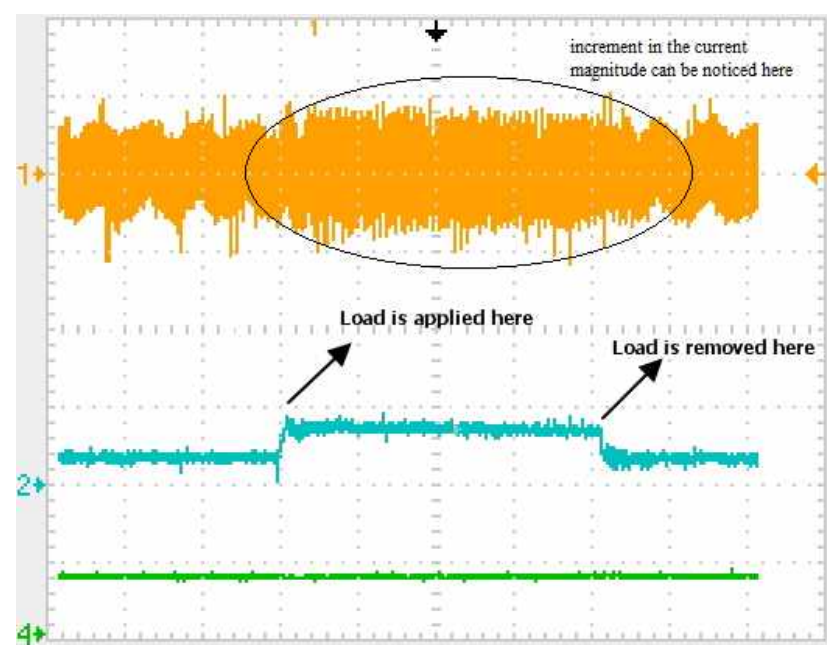

Fig. 18. Experimental results of the proposed DTC method 3 during external load disturbance.

vector combination, the torque ripple can be significantly reduced by up to $45.51 \%$ in the proposed DTC method. At the same time, this is seen without degrading the steady state performance.

Remark 6: From the results indicated earlier, it is found that the torque ripple in the proposed DTC methods are less when compared to the classical DTC method and the existing literature. At almost all of the operating points the classical DTC provides a slightly higher torque ripple (refer Fig. 14). However, the proposed DTC methods 3 and 4 show better performance in terms of torque ripple when compared to the classical DTC, the existing literature [26], [28] and all of the other proposed DTC methods (refer Table VI).

Remark 7: The major drawback reported in the literature concerning the classical DTC is that the torque ripple during low speed operation is very high. However, all of the proposed DTC methods provides less torque ripple even at low speeds, whereas the proposed DTC methods 3 and 4 provide much lesser torque ripple among the classical DTC method, all of the other proposed DTC methods and results reported in the existing literature.

Remark 8: All of the DTC methods exhibit similar decelerating capability. However, the proposed DTC 3 and 4 provide less THD in the current waveform.

Remark 9: All of the proposed and existing DTC methods show good disturbance rejection characteristics at the cost of higher torque ripple except the proposed DTC methods 3 and 4. This ensures the safe operation of the entire system.

Remark 10: The experimental results of the proposed DTC methods indicate that improvements in the area of digital implementation are required. As a result, further investigations are required.

\section{CONCLUSIONS}

In this paper, a novel switching table is proposed to minimize the torque ripple in the DTC of PMSM drives. The novel switching table, in which only any two / all of the voltage vectors (LZ, MZ, SZ and LMSZ) are utilized out of the four available voltage vectors $(L, M, S, Z)$ due to an increment in the level of the inverter. The performance of the proposed DTC method is comparatively investigated with the classical DTC and existing literatures. Simulations results prove that the proposed DTC methods are able to diminish the torque ripple at different operating points when compared to the classical DTC. Consequently, the proposed DTC methods also give satisfactory performance during external load disturbance operations. The proposed DTC methods are also capable of reducing the THD in the stator current. The settling time of the torque can be reduced when compared with the classical DTC method. Furthermore, the related current ripple is also reduced. The proposed DTC methods also retain the merits of simplicity and robustness found in DTC. The effectiveness of the proposed DTC method is also confirmed by experimental validation.

\section{REFERENCES}

[1] F. Blaschke, "The principle of field orientation as applied to the new TRANSVECTOR closed loop control system for rotating field machines," Siemens Rev., Vol. 34, pp. 217-220, 1972.

[2] I. Takahashi and T. Nogushi, "A new quick-response and high efficiency control strategy of an induction motor," IEEE Trans. Ind. Appl., Vol. IA-22, No. 5, pp. 820-827, Sep. 1986.

[3] M. Depenbrock, "Direct self-control (DSC) of inverter-fed induction machine," IEEE Trans. Power Electron., Vol. 3, No. 4, pp. 420-429, Oct. 1988.

[4] B. Cheng and T. R. Tesch, "Torque feed forward control technique for permanent-magnet synchronous motors," IEEE Trans. Ind. Electron., Vol. 57, No. 3, pp. 969-974, Mar. 2010.

[5] M. Tursini, E. Chiricozzi, and R. Petrella, "Feed forward flux-weakening control of surface-mounted permanent-magnet synchronous motors accounting for resistive voltage drop," IEEE Trans. Ind. Electron., Vol. 57, No. 1, pp. 440-448, Jan. 2010.

[6] C. Ortega, A. Arias, C. Caruana, J. Balcells, and G. M. Asher, "Improved waveform quality in the direct torque control of matrix-converter-fed PMSM drives," IEEE Trans. Ind. Electron., Vol. 57, No. 6, pp. 2101-2110, Jun. 2010.

[7] G. Foo and M. F. Rahman, "Sensorless sliding-mode MTPA control of an IPM synchronous motor drive using a sliding-mode observer and HF signal injection," IEEE Trans. Ind. Electron., Vol. 57, No. 4, pp. 1270-1278, Apr. 2010.

[8] G. S. Buja and M. P. Kazmierkowski, "Direct torque control of PWM inverter-fed AC motors - A survey," IEEE Trans. Ind. Electron., Vol. 51, No. 4, pp. 744-757, Aug. 2004.

[9] L. Zhong, M. Rahman, W. Hu, and K. Lim, "Analysis of direct torque control in permanent magnet synchronous motor drives," IEEE Trans.Power Electron., Vol. 12, No. 3, pp. 528-536, May 1997. 
[10] G. Foo and M. F. Rahman, "Sensorless direct torque and flux-controlled IPM synchronous motor drive at very low speed without signal injection," IEEE Trans. Ind. Electron., Vol. 57, No. 1, pp. 395-403, Jan. 2010.

[11] M. Pacas and J. Weber, "Predictive direct torque control for the PM synchronous machine," IEEE Trans. Ind. Electron., Vol. 52, No. 5, pp. 1350-1356, Oct. 2005.

[12] J.-K. Kang and S.-K. Sul, "New direct torque control of induction motor for minimum torque ripple and constant switching frequency," IEEE Trans. Ind. Appl., Vol. 35, No. 5, pp. 1076-1082, Sep./Oct. 1999

[13] G. Abad, M. A. Rodriguez, and J. Poza, "Two-level VSC based predictive direct torque control of the doubly fed induction machine with reduced torque and flux ripples at low constant switching frequency," IEEE Trans. Power Electron., Vol. 23, No. 3, pp. 1050-1061, May 2008.

[14] L. Romeral, A. Arias, E. Aldabas, and M. Jayne, "Novel direct torque control (DTC) scheme with fuzzy adaptive torque-ripple reduction," IEEE Trans. Ind. Electron., Vol. 50, No. 3, pp. 487-492, Jun. 2003.

[15] R. Morales-Caporal and M. Pacas, "Encoderless predictive direct torque control for synchronous reluctance machines at very low and zero speed," IEEE Trans. Ind. Electron., Vol. 55, No. 12, pp. 4408-4416, Dec. 2008.

[16] K.-K. Shyu, J.-K. Lin, V.-T. Pham, M.-J. Yang, and T.-W. Wang, "Global minimum torque ripple design for direct torque control of induction motor drives," IEEE Trans. Ind. Electron., Vol. 57, No. 9, pp. 3148-3156, Sep. 2010.

[17] E. Flach, R. Hoffmann, and P. Mutschler, "Direct mean torque control of an induction motor," in Proc. EPE, 1997, Vol. 3, pp. 672-677.

[18] G.-D. Andreescu, C. Pitic, F. Blaabjerg, and I. Boldea, "Combined flux observer with signal injection enhancement for wide speed range sensorless direct torque control of IPMSM drives," IEEE Trans. Energy Convers., Vol. 23, No. 2, pp. 393-402, Jun. 2008.

[19] Y. Zhang, Z. Zhao, T. Lu, and L. Yuan, "Sensorless 3-level inverter-fed induction motor drive based on indirect torque control," in Proc. IEEE 6th IPEMC Conf., 2009, pp. 589-593.

[20] L. Tang, L. Zhong, M. Rahman, and Y. Hu, "A novel direct torque controlled interior permanent magnet synchronous machine drive with low ripple in flux and torque and fixed switching frequency," IEEE Trans. Power Electron., Vol. 19, No. 2, pp. 346-354, Mar. 2004.

[21] D. Casadei, F. Profumo, G. Serra, and A. Tani, "FOC and DTC: Two viable schemes for induction motors torque control," IEEE Trans. Power Electron., Vol. 17, No. 5, pp. 779-787, Sep. 2002.

[22] S. Kouro, R. Bernal, H. Miranda, C. Silva, and J. Rodriguez, "High performance torque and flux control for multilevel inverter fed induction motors," IEEE Trans. Power Electron., Vol. 22, No. 6, pp. 2116-2123, Nov. 2007.

[23] K.-B. Lee and F. Blaabjerg, "An improved DTC-SVM method for sensorless matrix converter drives using an overmodulation strategy and a simple nonlinearity compensation," IEEE Trans. Ind. Electron., Vol. 54, No. 6, pp. 3155-3166, Dec. 2007.

[24] Y. Zhang, J. Zhu, Z. Zhao, W. Xu, and D. G. Drroell, “An improved direct torque control for three-level inverter-fed induction motor sensorless drive," IEEE Trans. Power Electron., Vol. 27, No. 3, Mar. 2012.

[25] Y. Zhang, J. Zhu, and W. Xu, "Predictive torque control of permanent magnet synchronous motor drive with reduced switching frequency," in Proc. Int. Conf. Electr. Mach. Syst., 2010, pp. 798-803.

[26] Y. Zhang and J. Zhu, "Direct torque control of permanent magnet synchronous motor with reduced torque ripple and commutation frequency," IEEE Trans. Power Electron., Vol. 26, No. 1, pp. 235-248, Jan. 2011.

[27] Y. Zhang, J. Zhu, W. Xu, and Y. Guo, "A simple method to reduce torque ripple in direct torque-controlled permanent-magnet synchronous motor by using vectors with variable amplitude and angle," IEEE Trans. Ind. Electron., Vol. 58, No. 7, pp. 2848-2859, 2011.

[28] Y. Zhang and J. Zhu, "A Novel Duty Cycle Control Strategy to Reduce Both Torque and Flux Ripples for DTC of Permanent Magnet Synchronous Motor Drives with Switching Frequency Reduction," IEEE Trans. Power Electron., Vol. 26, No. 10, pp. 3055-3067, Oct. 2011.

[29] M. Nasir Uddin and M. Hafeez, "FLC-Based DTC Scheme to Improve the Dynamic Performance of an IM Drive", IEEE Trans. Ind. Appl., Vol. 48, No. 2, pp. 823-831, Mar./Apr. 2012.

[30] S. Mathapati and J. Bocker, "Analytical and Offline Approach to select Optimal Hysteresis Bands of DTC for PMSM", IEEE Trans. Ind. Electron., Vol. 60, No. 3, pp. 885-895, Mar. 2013.

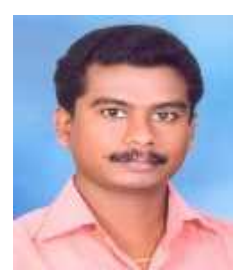

Sivaprakasam Arumugam received his B.E. from Madurai Kamarj University, India, in 2001, and his M.E. from the PSG College of Technology, Coimbatore, India, in 2003. $\mathrm{He}$ is currently an Assistant Professor (Selection Grade) in the Electrical and Electronics Engineering Department, Kongu Engineering College, Erode, India. His current research interests include the analysis of electrical machines, power electronics, and sensorless and high performance control of special electrical machines.

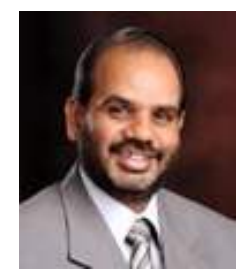

Manigandan Thathan received his B.E. from the Government College of Technology, Coimbatore, India, in 1996, his M.E. from the PSG College of Technology, Coimbatore, India, in 1998, and his Ph.D. from Anna University, Chennai, India, in 2005. He is currently the Principal of the P. A. College of Engineering and Technology, Pollachi, India. He has published over 150 referenced technical papers including journal articles. His current research interests include the modeling of electrical systems, stability analysis of electrical systems, and advanced digital control with real time implementations. 